Research Article

\title{
Thin Film Flow of Tangent Hyperbolic Fluid with Nonlinear Mixed Convection Flow and Entropy Generation
}

\author{
Wubshet Ibrahim (iD) and Tezera Gizewu \\ Department of Mathematics, Ambo University, Ambo, Ethiopia \\ Correspondence should be addressed to Wubshet Ibrahim; wubshetib@yahoo.com
}

Received 5 June 2021; Revised 18 July 2021; Accepted 8 September 2021; Published 26 September 2021

Academic Editor: Babak Shotorban

Copyright (c) 2021 Wubshet Ibrahim and Tezera Gizewu. This is an open access article distributed under the Creative Commons Attribution License, which permits unrestricted use, distribution, and reproduction in any medium, provided the original work is properly cited.

\begin{abstract}
This paper examined the three-dimensional steady thin film flow of tangent hyperbolic fluid with nonlinear mixed convection flow and entropy generation past a stretching surface under the influence of magnetic field. For the flow problem, the CattaneoChristov heat and mass diffusion model was employed to examine heat and mass transfer characteristics and impacts of the normally directed magnetic field. To transform nonlinear PDEs into ODEs, the variable transformation technique was used. The bvp4c algorithm was implemented to solve these ODEs. The behavior of every leading parameter on the velocities, temperature, concentration profile, entropy generation, and Bejan number was reported with tabular and figurative form. The results show that as the values of $\mathrm{Br}$ increase, the entropy generation enhances, but the Bejan number decreases. Moreover, as the values of $B$ increase, the opposite characteristics are observed in entropy generation and Bejan number graphs. Furthermore, the skin friction coefficient number, local Nusselt number, and Sherwood number are graphically discussed for the active involved parameters. The best agreement is recorded when we compare this paper with the previous literature for various values of $M$.
\end{abstract}

\section{Introduction}

In physical sciences, one of the essential factors of flow of fluid which has very common applications is entropy generation. In different fields of sciences and technologies, some researchers have done a lot of work on it. In case of thin film fluid flow, very little work is available in the literature. The entropy productions due to transmission of convective heating were reported by Bejan $[1,2]$ for the first time. Later on, Lin et al. [3] examined the compressible flow through a high pressure turbine for local entropy generation due to delayed detached eddy simulation. Further, Khan et al. [4] studied entropy generation of rotating disks due to bioconvection flow of nanofluid. Opanuga et al. [5] have also carried out a study on entropy generation analysis with the effect of ion-slip and hall current of couple stress fluid. Moreover, Bibi and Xu [6] have discussed entropy generation analysis of Jeffrey nanofluid under magnetic field effect on horizontal channel.

The study of entropy generation analysis nowadays is an active research area. Accordingly, Ji et al. [7] have presented performance evaluation of entropy generation due to forced convective heat transfer. Shit et al. [8] also investigated entropy generation performance under the effect of thermal radiation and unsteady flow over a flat plate. Gireesha et al. [9] have presented a study on entropy generation with inclined porous microchannel for Casson fluid flow with viscous and Joule heating. Muhammad and Sohail [10] have computed entropy generation under the impact of radiative heat transfer on rotating disks with Ree-Eyring fluid. Leonid and Martyushev [11] have analyzed the misconception about the production of entropies. A report on nonequilibrium thermodynamics with productions of entropy has been presented by Velasco et al. [12]. Gallavotti [13] has computed stationary states of nonequilibrium in a point of view. Additionally, Kurnia et al. [14] have studied the cooling of microchannel with heat transfer performance on entropy production, and Şahin [15] has numerically explored entropy generation in a square cavity filled with boron-water nanofluid. Moreover, Soltanipour et al. [16] have numerically examined ferrofluid forced convection with magnetic field and entropy generation in a curved pipe. Additionally, 
Riaz et al. [17] have investigated the features of entropy generation and applied magnetic field in an annular part of two micro nonconcentric pipes on Jeffrey fluid with the inner one being of rigid nature traveling for uniform speed, and Riaz et al. [18] have discussed the entropy generation and Williamson fluid on the asymmetric peristaltic propulsion of non-Newtonian fluid with convective boundary conditions.

The attention of most recent researchers is focused on the study of flow and heat transfer in a thin liquid film on a stretching surface with its numerous applications in industrial and engineering fields. In manufacturing processes of aerodynamic extrusion of plastic sheets, foodstuff processing, fibre coating, reactor fluidization, annealing, and thinning of copper wires in relation to fluid flow and heat transfer within a thin liquid film are very important. It is essential to maintain surface quality of the extubate in the process of extrusion of materials. The best appearance with strength, good translucency, and low impeding friction for producing smooth glossy surfaces for all coating processes is necessary for a thin film. The behavior of flow and heat transfer in thin film is determined by the quality of the end product in the extrusion process of the fluid flow and heat transfer characteristics on stretching sheet. Gul et al. [19] have analyzed thin film flow and entropy generation over a stretching sheet with variable fluid properties. Sarojamma et al. [20] and Shah et al. [21] have discussed the influence of magnetic field on thin film flow and the generation of entropy for unsteady flow of Newtonian and non-Newtonian fluid over stretching sheet.

The attention of scientists and engineers in recent years is attracted by the magnetohydrodynamic (MHD) phenomenon owing to its realistic application in MHD electric transformers, accelerators, and cooling of a metallic plate. Natural convection flow with electrically conducting fluid past different geometries with different fluids has been studied widely in most of the literature. Despite the fact that there are numerous studies on natural convection flow of electrically conducting fluid, there are just a few studies regarding natural convection flow of an electrically conducting tangent hyperbolic fluid. Consistent magnetic environment with steered square geometry under mixed convection thermal transfer and micropolar liquid material is discussed by Siddiqui et al. [22], and tha et al. [23] have investigated magnetohydrodynamic flow in a vertical microchannel with hall effect under natural convection flow. Moreover, Khatera et al. [24] presented the impact of magnetic field diffusion using cylindrical coordinates system of Fokker-Planck equation which relates potential symmetry and invariant solution. Furthermore, $\mathrm{Pal}$ and Talukdar [25] have solved the problem of rotating porous channel with the effect of magnetic field, convective heat and mass transfers, hall current, and thermal radiation. Abiodun et al. [26] have checked MHD micropolar fluid with effect of hall current and analysis of entropy production. Liao et al. [27] have reported a numerical study on magnetohydrodynamics with planetary spheres. Basant et al. [28] have computed flow of magnetohydrodynamics with ion-slip current at vertical microchannel. Barik et al. [29], Yeh et al.
[30], Usman et al. [31], Singh and Bhardwaj [32], and Kumar et al. [33] have numerically computed the effect of chemical reaction, free convection, and magnetic field on heat and mass transfer phenomenon past different geometry with different initial and boundary conditions for different kinds of fluids.

Mixed convection is the combined influence of both free and forced convection. Most technical applications of it have been discovered by some of the following researchers. Accordingly, Shayma and Litan [34] have analyzed incompressible fluid past a wedge with boundary layer flow mixed convection transient under magnetic field effects. Rashed et al. [35] have also investigated temperature distribution of a vertical porous annulus with mixed convection opposing flow. Arani et al. [36] and Mohamed et al. [37] also presented mixed convection, optimal distribution of heat transfer, and viscous dissipation effect of discrete heat sources. Alsabery et al. [38] have checked mixed convection flow and entropy generation for a heat source and rotating solid cylinder inside a wavy-walled enclosure. Wubshet and Temesgen [39] have reported Eyring-Powell nanofluid with ion-slip and hall effects under stretching sheet. Hashmi et al. [40] have computed mixed convection flow with homogeneous heterogeneous reactions of magnetized Maxwell fluid. Sajida et al. [41] have studied viscoelastic fluid under mixed convection flow of permeable parallel vertical plates. Basant et al. [42] have examined temperature dependent of vertical channel under viscosity and flow reversal of mixed convection flow. Ahmad et al. [43] have introduced Jeffrey fluid on mixed convection flow for magnetohydrodynamic effects with exponentially stretching surface. Khan et al. [44] have carried out a theoretical analysis for mixed convection flow of Maxwell fluid between two infinite isothermal stretching disks. Basant et al. [45] have analyzed mixed convection flow on hall and ion-slip effects with wall heating at vertical microchannel. Additionally, Jawali et al. [46] have investigated mixed convection flow with Soret effects under condition of Robin boundary conditions. Wubshet and Gosa [47] have presented inclined stretching cylinder with mixed convective flow under Cattaneo-Christov heat flux theory. Ashraf et al. [48] have solved three-dimensional mixed convection radiative flow in presence of convective condition and thermophoresis stretching sheet. Shah and Dennis [49] have solved mixed convection flow of vertical plate under oscillating of heat transfer analysis. Moreover, Khan et al. [50] have checked nonlinear mixed convection flow of tangent hyperbolic fluid and entropy generation optimization under activation energy stretching sheet. In many engineering and industrial processes, such as food mixing, multigrade oils, plasma, and composite materials, nonNewtonian fluids are found. For those applications, many researchers concentrated on non-Newtonian fluids. Hyperbolic tangent fluid is considered the best one of branches of the non-Newtonian fluid which is capable of describing the thinning shear effects. Recently, Kumar et al. [51] have reported the dusty flow of hyperbolic tangent fluid with magnetic field and thermal radiation over stretching sheet. Naseer et al. [52] have computed the hyperbolic tangent fluid with boundary layer flow of cylindrical stretching sheet. 
Khan et al. [53] have introduced double stratification tangent hyperbolic fluid flow under radiation and chemical reaction. Shahzad et al. [54] have developed MHD tangent hyperbolic fluid with Joule heating, viscous dissipation, and chemical reaction. Naseer et al. [55] have analyzed hyperbolic tangent fluid of cylinder under vertical stretching surface. Hayat et al. [56] have investigated Soret-Dufour effects on hyperbolic tangent fluid flow at stagnation point. Kumar et al. [57], Rehman et al. [58], and Hayat et al. [59] have studied tangent hyperbolic fluid under the effects of unsteady flow, variable thermal conductivity, Joule heating, and thermal radiation. Nadeem et al. [60] also reported magnetohydrodynamic peristaltic flow in a vertical asymmetric channel with heat transfer. Additionally, Akbar et al. [61] and Hussain et al. [62] have examined the effects of convective heating and nonlinear stretching parameters on the MHD boundary layer flow analysis of tangent hyperbolic fluid. Furthermore, behavior of incompressible magnetohydrodynamic flow tangent hyperbolic fluid with the effect of melting heat transfer in the stagnation point has been reported by Hayat et al. [63], and the analysis of tangent hyperbolic material in the presence of both nanoparticles past an exponential surface with the heat, mass, and motile microorganisms transfer rate in the magnetohydrodynamic convective flow has been performed by Shafiq et al. [64]. Moreover, Alaidrous et al. [65] and Ibrahim and Gizewu $[66,67]$ have studied tangent hyperbolic nanofluid past bidirectional extending surface under the application of some physical conditions such as thermal radiation, Joule heating, activation energy, and chemical reaction of high order by employing Cattaneo-Christov heat flux model. To our knowledge, no one has attempted to investigate the effect of three-dimensional thin film flow of tangent hyperbolic fluid with nonlinear mixed convection flow and entropy generation past stretching surface.

\section{Mathematical Formulation}

This paper deals with three-dimensional flow of hyperbolic tangent fluid thin film. The fluid satisfies the condition of incompressible, steady, laminar, and viscous flow due to entropy generation and mixed convection with applied magnetic field in the perpendicular direction. For the flow formulation, Cattaneo-Christov heat and mass diffusion model is employed for the examination of heat and mass transfer characteristics. $o x$ and $o y$ are established as $z$ is normal to the surface in the Cartesian coordinate system. Magnitudes of velocities at $z=0$ are $U_{w}=e x$ and $V_{w}=e y$ where $e<0$ represents the contraction of the sheet and $e>0$ represents the stretching of the sheet. In this article, the description of temperature field and the concentration distribution are defined as $T_{w}=T_{0} T_{\text {ref }}\left(e x^{2} / 2 \nu\right)$ and $C_{w}=C_{0} C_{\text {ref }}\left(e x^{2} / 2 \nu\right)$, where $T_{0}, C_{0}, T_{\text {ref }}$, and $C_{\text {ref }}$ are demonstrated by the temperature at the surface of a sheet, the nanofluid concentration at the surface of a sheet, the constant reference temperature, and the constant reference concentration, respectively, as shown in Figure 1.

Constitutive equation of non-Newtonian fluid which is assumed in this article is presented by [66] as follows:

$$
\gamma=\left[\eta_{\infty}+\left(\eta_{\infty}+\eta_{0}\right) \tanh (\Phi \Psi)^{r}\right] \Psi
$$

where $\Psi$ is defined as

$$
\Psi=\sqrt{\frac{1}{2} \sum_{i} \sum_{j} \Psi_{i j} \Psi_{j i}}=\sqrt{\frac{1}{2} \dot{\Upsilon}},
$$

for

$$
\begin{aligned}
& \dot{\Upsilon}=\frac{1}{2} \operatorname{tr}\left(\operatorname{grad} V+(\operatorname{grad} V)^{T}\right)^{2} \\
& \dot{\Upsilon}=\frac{1}{2} \operatorname{tr}\left(\nabla V+(\nabla V)^{T}\right)^{2} .
\end{aligned}
$$

The equation is assumed when $\eta_{\infty}=0$ and $\Phi \Psi \ll 1$; by using this idea, (1) becomes

$$
\begin{aligned}
& \gamma=\eta_{0}\left[(\Phi \Psi)^{r}\right] \Psi=\eta_{0}\left[(1+\Phi \Psi-1)^{r}\right] \Psi=\eta_{0}[1+(\Phi \Psi-1) r] \Psi, \\
& \gamma=\eta_{0}[1+r(\Phi \Psi-1)] \Psi,
\end{aligned}
$$

where $\gamma, \eta_{0}, \eta_{\infty}, \Phi, r, \dot{\Upsilon}$, and $\Psi$ are extra stress tensor, zero shear rate viscosity, infinity shear rate viscosity, time constant, dimensionless power-law index, strain rate tensor of second invariant, and shear-thinning characteristics which represent tangent hyperbolic fluid being considered, respectively.

Governing equations of this problem are defined as follows:

$$
\begin{aligned}
\frac{\partial u}{\partial x}+\frac{\partial v}{\partial y}+\frac{\partial w}{\partial z}= & 0 \\
u \frac{\partial u}{\partial x}+v \frac{\partial u}{\partial y}+w \frac{\partial u}{\partial z}= & (1-r) v \frac{\partial^{2} u}{\partial z^{2}}+\sqrt{2} r v \Phi \frac{\partial u}{\partial z}\left(\frac{\partial^{2} u}{\partial z^{2}}\right)-\frac{\sigma B_{0}^{2}}{\rho_{f}}(u) \\
& -g\left[\tau_{1}\left(T_{\infty}-T\right)+\tau_{3}\left(C_{\infty}-C\right)+\tau_{2}\left(T_{\infty}-T\right)^{2}+\tau_{4}\left(C_{\infty}-C\right)^{2}\right] \\
u \frac{\partial v}{\partial x}+v \frac{\partial v}{\partial y}+w \frac{\partial v}{\partial z}= & (1-r) v \frac{\partial^{2} v}{\partial z^{2}}+\sqrt{2} r v \Phi \frac{\partial v}{\partial z}\left(\frac{\partial^{2} v}{\partial z^{2}}\right)-\frac{\sigma B_{0}^{2}}{\rho_{f}}(v)
\end{aligned}
$$




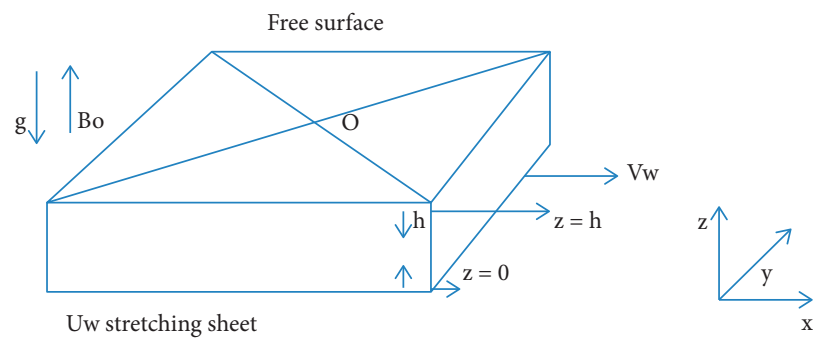

Figure 1: Physical model of the problem.

The equations of Cattaneo-Christov heat and mass model flux as used by [67] are

$$
\begin{aligned}
& \varphi_{q}\left(\frac{\partial q}{\partial t}+V \cdot \nabla q-q \cdot \nabla V+(\nabla \cdot V) q\right)=-\left(k_{f} \nabla T+q\right) \\
& \varphi_{J}\left(\frac{\partial J}{\partial t}+V \cdot \nabla J-J \cdot \nabla V+(\nabla \cdot V) J\right)=-\left(D_{B} \nabla C+J\right) .
\end{aligned}
$$

$\varphi_{q}, \varphi_{J} ; q ; T ; J ; C$; and $k_{f}$ are the relaxation time parameter for the heat flux and mass flux, the heat flux, the temperature of the fluid, mass flux, concentration of the fluid, and thermal conductivity of the fluid, respectively.

$$
\begin{aligned}
& u \frac{\partial T}{\partial x}+v \frac{\partial T}{\partial y}+w \frac{\partial T}{\partial z}=-\varphi_{q}\left(\chi_{q}\right)+\frac{1}{\rho C_{p}}\left(\frac{\partial}{\partial z}\right)\left(k_{0} \frac{\partial T}{\partial z}\right)+\varphi\left\{D_{B}\left(\frac{\partial C}{\partial y} \frac{\partial T}{\partial y}\right)+\frac{D_{T}}{T_{\infty}}\left[\left(\frac{\partial T}{\partial z}\right)^{2}\right]\right\} \\
& \cdot(1-r) v\left(\frac{\partial^{2} u}{\partial z^{2}}+\frac{\partial^{2} v}{\partial z^{2}}\right)+\sqrt{2} r v \Phi\left(\frac{\partial u}{\partial z}\left(\frac{\partial^{2} u}{\partial z^{2}}\right)+\frac{\partial v}{\partial z}\left(\frac{\partial^{2} v}{\partial z^{2}}\right)\right)+\frac{\sigma B_{0}^{2}}{\rho_{f}}(u) \\
& u \frac{\partial C}{\partial x}+v \frac{\partial C}{\partial y}+w \frac{\partial C}{\partial z}=-\varphi_{J}\left(\chi_{J}\right)+D_{B}\left(\frac{\partial^{2} C}{\partial z^{2}}\right)+\frac{D_{T}}{T_{\infty}}\left(\frac{\partial^{2} T}{\partial z^{2}}\right)
\end{aligned}
$$

where $\chi_{q}$ and $\chi_{J}$ are defined as

$$
\begin{aligned}
\chi_{q}= & u^{2} \frac{\partial^{2} T}{\partial x^{2}}+\left(u \frac{\partial u}{\partial x}+v \frac{\partial u}{\partial y}+w \frac{\partial u}{\partial z}\right) \frac{\partial T}{\partial x}+v^{2} \frac{\partial^{2} T}{\partial y^{2}}+\left(u \frac{\partial v}{\partial x}+v \frac{\partial v}{\partial y}+w \frac{\partial v}{\partial z}\right) \frac{\partial T}{\partial y}+w^{2} \frac{\partial^{2} T}{\partial z^{2}} \\
& +\left(u \frac{\partial w}{\partial x}+v \frac{\partial w}{\partial y}+w \frac{\partial w}{\partial z}\right) \frac{\partial T}{\partial z}+2 u v \frac{\partial^{2} T}{\partial x \partial y}+2 w\left(u \frac{\partial^{2} T}{\partial x \partial z}+v \frac{\partial^{2} T}{\partial y \partial z}\right), \\
\chi_{J}= & u^{2} \frac{\partial^{2} C}{\partial x^{2}}+\left(u \frac{\partial u}{\partial x}+v \frac{\partial u}{\partial y}+w \frac{\partial u}{\partial z}\right) \frac{\partial C}{\partial x}+v^{2} \frac{\partial^{2} C}{\partial y^{2}}+\left(u \frac{\partial v}{\partial x}+v \frac{\partial v}{\partial y}+w \frac{\partial v}{\partial z}\right) \frac{\partial C}{\partial y}+w^{2} \frac{\partial^{2} C}{\partial z^{2}} \\
& +\left(u \frac{\partial w}{\partial x}+v \frac{\partial w}{\partial y}+w \frac{\partial w}{\partial z}\right) \frac{\partial C}{\partial z}+2 u v \frac{\partial^{2} C}{\partial x \partial y}+2 w\left(u \frac{\partial^{2} C}{\partial x \partial z}+v \frac{\partial^{2} C}{\partial y \partial z}\right) .
\end{aligned}
$$




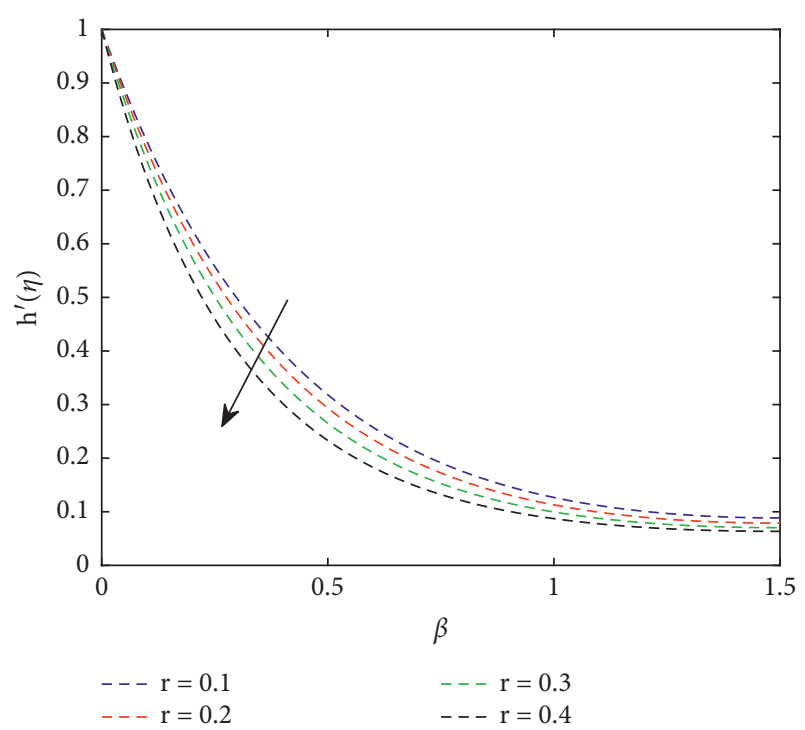

FIgURE 2: Characteristics of $r$ on velocity profile along $x$-direction.

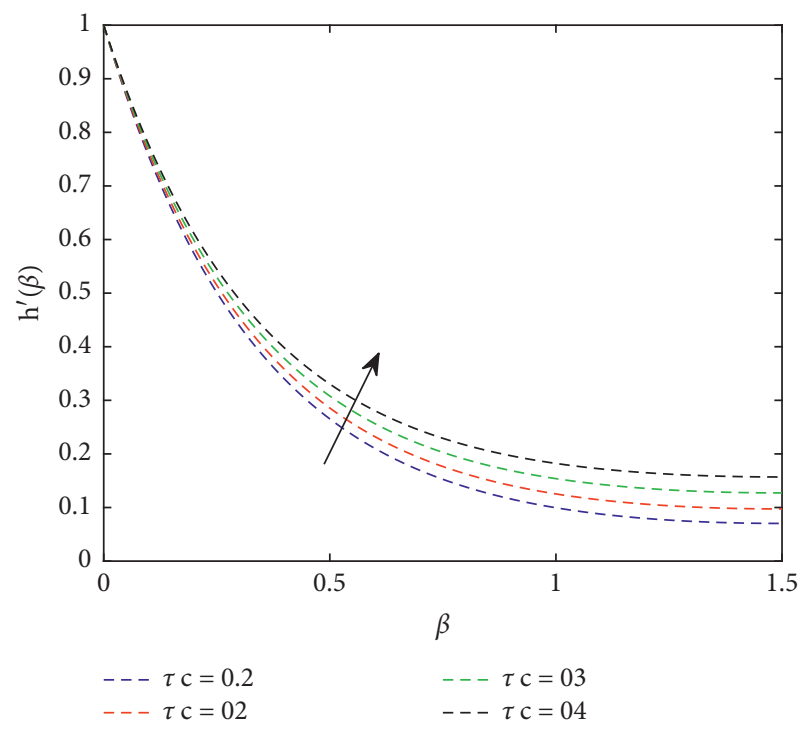

FIGURE 3: Characteristics of $\tau c$ on velocity profile along $x$-direction.

The boundary condition announcement by [19] in case of the present flow model is given as follows:

$$
\begin{aligned}
u & =U_{w}, v=V_{w}, w=0, T=T_{w}, C=C_{w}, \text { at } z=0 \\
\frac{\partial u}{\partial z} & =\frac{\partial v}{\partial z}=\frac{\partial T}{\partial z}=\frac{\partial C}{\partial z}=0, \text { at } z=h . \\
w & =u \frac{\mathrm{d} h}{\mathrm{~d} x}+u \frac{\mathrm{d} h}{\mathrm{~d} y}
\end{aligned}
$$

Similarity transformations used by [19] are given as

$$
\begin{aligned}
u & =\operatorname{exh}^{\prime}(\eta), \\
v & =e y k^{\prime}(\eta), \\
w & =-\sqrt{e v}(h(\eta)+k(\eta)), \quad \eta=\sqrt{\frac{e}{\nu}} z, \\
T(x, y, z) & =T_{0}-T_{\operatorname{ref}}\left(\frac{e x^{2}}{2 \nu}\right) \theta(\eta),
\end{aligned}
$$$$
C(x, y, z)=C_{0}-C_{\mathrm{ref}}\left(\frac{e x^{2}}{2 \nu}\right) \phi(\eta) .
$$

The flow equations as a result of conservation principles such as momentums, energy, and concentration are the following equations, respectively.

$$
\begin{gathered}
(1-r) h^{\prime \prime \prime}+(h+k) h^{\prime \prime}-\left(h^{\prime}\right)^{2}-M h^{\prime}+r W_{e} h^{\prime \prime} h^{\prime \prime \prime}+\left(1+\tau_{t} \theta\right) \lambda \theta+\left(1+\tau_{c} \phi\right) \beta \tau_{n} \phi=0, \\
(1-r) k^{\prime \prime \prime}+(h+k) k^{\prime \prime}-k^{\prime 2}-M k^{\prime}+r W_{e} k^{\prime \prime} k^{\prime \prime \prime}=0 \\
\theta^{\prime \prime}+\theta^{\prime} p_{r}(h+k)-p_{r} \delta_{e}\left(\theta^{\prime}(h+k)\left(h^{\prime}+k^{\prime}\right)+\theta^{\prime \prime}(h+k)^{2}\right)+\phi^{\prime} \theta^{\prime} p_{r} N b \\
+\theta^{\prime 2} p_{r} \mathrm{Nt}+M\left(h^{\prime}+k^{\prime}\right)+(1-r)\left(h^{\prime \prime \prime}+k^{\prime \prime \prime}\right)+r W_{e}\left(h^{\prime \prime} h^{\prime \prime \prime}+k^{\prime \prime} k^{\prime \prime \prime}\right)=0 \\
\phi^{\prime \prime}+\phi^{\prime} \mathrm{Sc}(h+k)+\frac{N_{t}}{N_{b}} \theta^{\prime \prime}-\mathrm{Sc}_{c}\left(\left(h^{\prime}+k^{\prime}\right) \phi^{\prime}(h+k)+\phi^{\prime \prime}(h+k)^{2}\right)=0 .
\end{gathered}
$$


Thickness of film of a flowing liquid in nondimensional form $(\beta)$ is $\beta=(e / v)^{1 / 2} h$ by considering $\beta=\eta$ the unknown parameter to determine the boundary of the problem according to the next equation:

$$
\begin{aligned}
h(0) & =k(0)=0, \\
h^{\prime}(0) & =1=k^{\prime}(0)=\theta(0)=\phi(0), \\
h(\beta) & =0=k(\beta)=h^{\prime \prime}(\beta)=k^{\prime \prime}(\beta)=\theta^{\prime}(\beta)=\phi^{\prime}(\beta),
\end{aligned}
$$

where the governing parameters are

$$
\begin{aligned}
& \mathrm{Nb}=\frac{\tau D_{T}}{v T_{h}}\left(T_{w}-T_{h}\right), \\
& \mathrm{Nt}=\frac{\tau D_{B}}{v}\left(C_{w}-C_{h}\right), \\
& M=\frac{\alpha B_{0}^{2}}{\rho e}, \\
& \mathrm{Sc}=\frac{v}{D_{B}}, \\
& \operatorname{Pr}=\frac{v}{\alpha_{D}}, \\
& \mathrm{We}=\sqrt{2} r \Gamma \sqrt{\frac{e^{3}}{v}} x \\
& \delta_{e}=e \chi_{q}, \\
& \delta_{c}=e \chi_{J}, \\
& \lambda=\frac{\mathrm{Gr}}{\operatorname{Re}_{x}^{2}}, \\
& \tau t=\frac{B t_{2}^{2} T_{0}}{B t_{1}^{2}}, \\
& \tau c=\frac{B c_{2}^{2} C_{0}}{B c_{1}^{2}}, \\
& \tau n=\frac{B c_{1}^{2} C_{0}}{B t_{1}^{2} T_{0}} .
\end{aligned}
$$

The skin friction coefficient $\left(c_{f}\right)$, the local Nusselt number $\left(\mathrm{Nu}_{x}\right)$, and the local Sherwood number $\left(\mathrm{Sh}_{x}\right)$ are physical quantities as used by [67], defined as follows:

$$
\begin{aligned}
c_{f} & =\frac{\tau_{w}}{\rho u_{w}^{2}}, \\
\mathrm{Nu}_{x} & =\frac{x q_{w}}{k_{0}\left(T_{W}-T_{\infty}\right)}, \\
\mathrm{Sh}_{x} & =\frac{x h_{w}}{k_{0}\left(C_{W}-C_{\infty}\right)},
\end{aligned}
$$

when

$$
\begin{aligned}
\gamma_{w} & =(1-r)\left[\frac{\partial u}{\partial z}+\frac{\partial v}{\partial z}\right]+\frac{r \Phi}{\sqrt{2}}\left[\left(\frac{\partial u}{\partial z}\right)^{2}+\left(\frac{\partial v}{\partial z}\right)^{2}\right], \\
q_{w} & =-k_{0}\left(\frac{\partial T}{\partial z}\right)_{z=0}, \\
h_{w} & =-D_{B}\left(\frac{\partial C}{\partial z}\right)_{z=0}, \\
\left(R_{e_{x}}\right)^{0.5} c_{f_{x}} & =\left((1-r)+\frac{r W_{e}}{2} h^{\prime \prime}(0)\right) h^{\prime \prime}(0), \\
\mathrm{Nu}_{x}\left(R_{e_{x}}\right)^{-0.5} & =-\theta^{\prime}(0), \\
\operatorname{Sh}_{x}\left(R_{e_{x}}\right)^{-0.5} & =-\phi^{\prime}(0), \quad \text { when } R_{e_{x}}=\frac{U_{x}(x+e)}{v} .
\end{aligned}
$$

2.1. Entropy Generation Analysis. Thermal irreversibility of the system is measured by systems of entropy generation. Mathematically, the present model of the entropy generation rate per unit volume is given in [19]. This model is used to reduce entropy generation of physical parameters in any scientific and engineering applications by controlling the output.

$$
\begin{aligned}
N_{G}= & \frac{k_{0}}{T \rho C_{p}}\left(\frac{\partial T}{\partial z}\right)^{2}+\frac{D_{B}}{T}\left(\frac{\partial C}{\partial y} \frac{\partial T}{\partial y}\right)+\frac{D_{B}}{T}\left(\frac{\partial C}{\partial z}\right)^{2} \\
& +\left\{\frac{(1-r) v}{T}\left(\left(\frac{\partial u}{\partial z}\right)^{2}+\left(\frac{\partial v}{\partial z}\right)^{2}\right)+\frac{\sqrt{2} r \nu \Phi}{T}\left(\frac{\partial u}{\partial z}\left(\frac{\partial u}{\partial z}\right)^{2}+\frac{\partial v}{\partial z}\left(\frac{\partial v}{\partial z}\right)^{2}\right)\right\}+\frac{\sigma B_{0}^{2}}{T \rho_{f}}(u),
\end{aligned}
$$




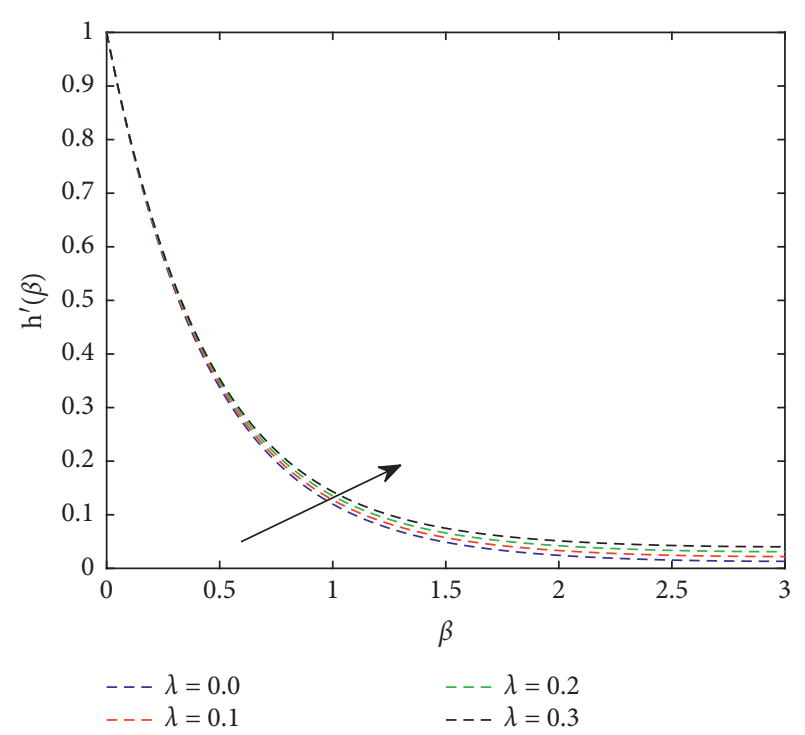

FIGURE 4: Characteristics of $\lambda$ on velocity profile along $x$-direction.

where representation of entropy generation due to the first term is thermal irreversibility, the second term is nanoparticle interdependence with base fluid, the third term is local mass transfer of the nanoparticle volume fraction, the

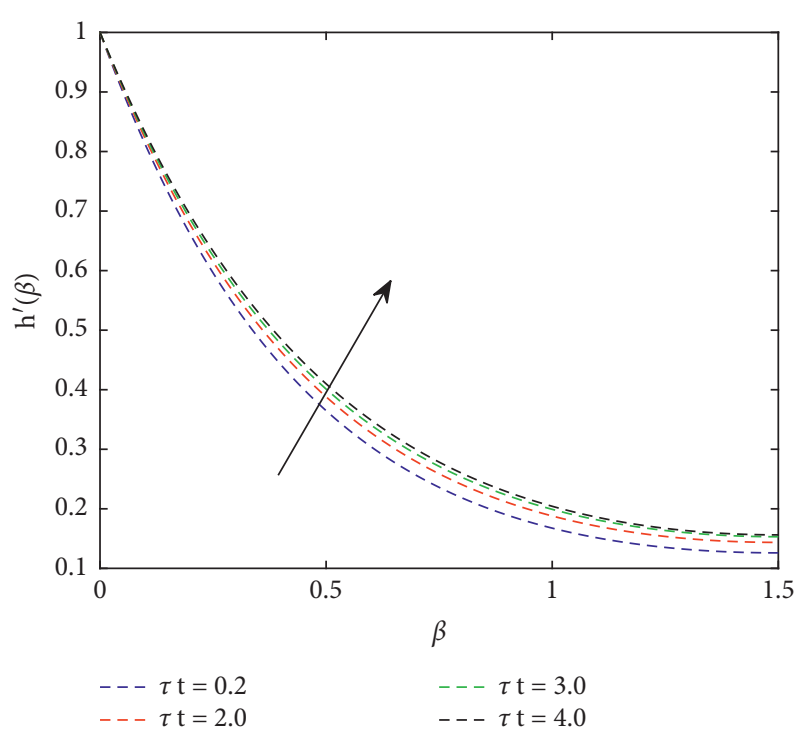

FIGURE 5: Characteristics of $\tau t$ on velocity profile along $x$-direction.

fourth term is the viscous dissipation, and the fifth term is the magnetic field, respectively, in the above equation.

Dimensionless form of the entropy generation can be expressed as follows by using the similarity transformation.

$$
\begin{aligned}
N_{G} & =\beta_{1} \theta^{\prime 2}+L_{1} \phi^{\prime} \theta^{\prime}+L_{1} \frac{\beta_{2}}{\beta_{1}} \phi^{\prime}+(1-r) B_{r}\left[h^{\prime \prime 2}+k^{\prime \prime 2}\right]+\frac{W_{e} B_{r}}{2}\left[h^{\prime \prime 3}+k^{\prime \prime 3}\right]+B_{r} M h^{\prime 2}, \\
N_{G} & =\frac{T_{\infty} S_{G} \nu}{\Delta T e \dot{k}} \\
L_{1} & =\frac{\Delta C R D}{\dot{k}} \\
\beta_{1} & =\frac{\Delta T}{T_{\infty}} \\
\beta_{2} & =\frac{\Delta C}{C_{\infty}} \\
B_{r} & =\frac{\mu e^{2} x^{2}}{\triangle T \dot{k}}
\end{aligned}
$$

where the representations of temperature difference variable, concentration difference parameter, Brinkman number, Diffusion parameter, and entropy generation are given as $\beta_{1}, \beta_{2}, B_{r}, L_{1}$, and $N_{G}$, respectively.
Bejan number for locality of quantifying the irreversibility of heat transfer process is now appropriate to be determined. Mathematically, the Bejan number in the boundary layer is defined by [32] according to the following equation:

$$
\begin{aligned}
& \mathrm{Be}=\frac{\text { entropy generation owing to heat and mass transfers }}{\text { total entropy generation }}, \\
& \mathrm{Be}=\frac{\beta_{1} \theta^{\prime 2}+L_{1} \phi^{\prime} \theta^{\prime}+L_{1}\left(\beta_{2} / \beta_{1}\right) \phi^{\prime}}{\beta_{1} \theta^{\prime 2}+L_{1} \phi^{\prime} \theta^{\prime}+L_{1}\left(\beta_{2} / \beta_{1}\right) \phi^{\prime}+(1-r) B_{r}\left[h^{\prime \prime 2}+k^{\prime \prime 2}\right]+\left(W_{e} B_{r} / 2\right)\left[h^{\prime \prime 3}+k^{\prime \prime 3}\right]+B_{r} M h^{\prime 2}} .
\end{aligned}
$$




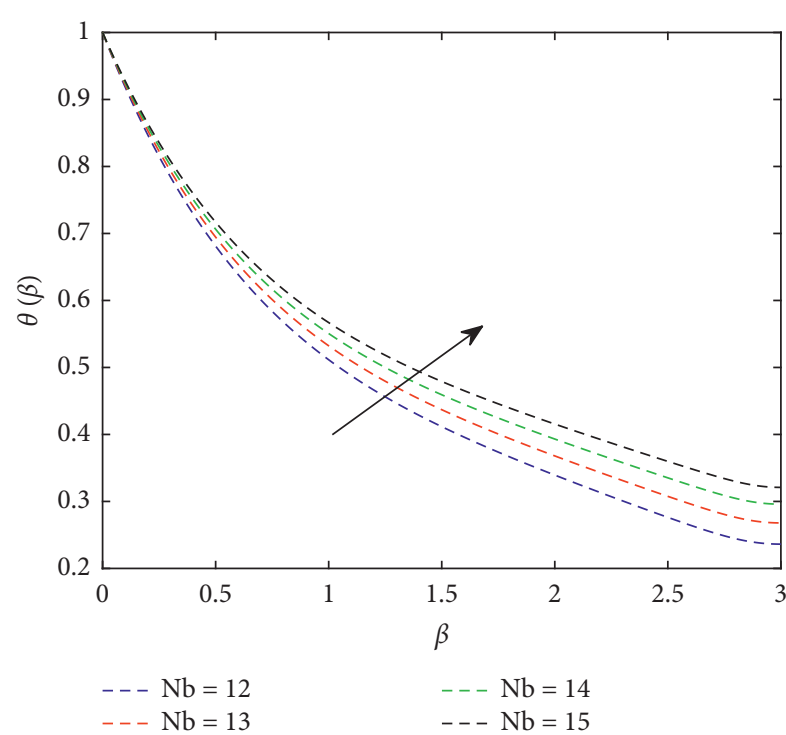

FIgURE 6: Characteristics of $\mathrm{Nb}$ on temperature profile.

\section{Numerical Method}

The bvp4c method is used to solve the converted ODEs of the problem, considering $h=f_{1}, h^{\prime}=f_{2}, \quad h^{\prime \prime}=f_{3}, \quad k=f_{4}$,

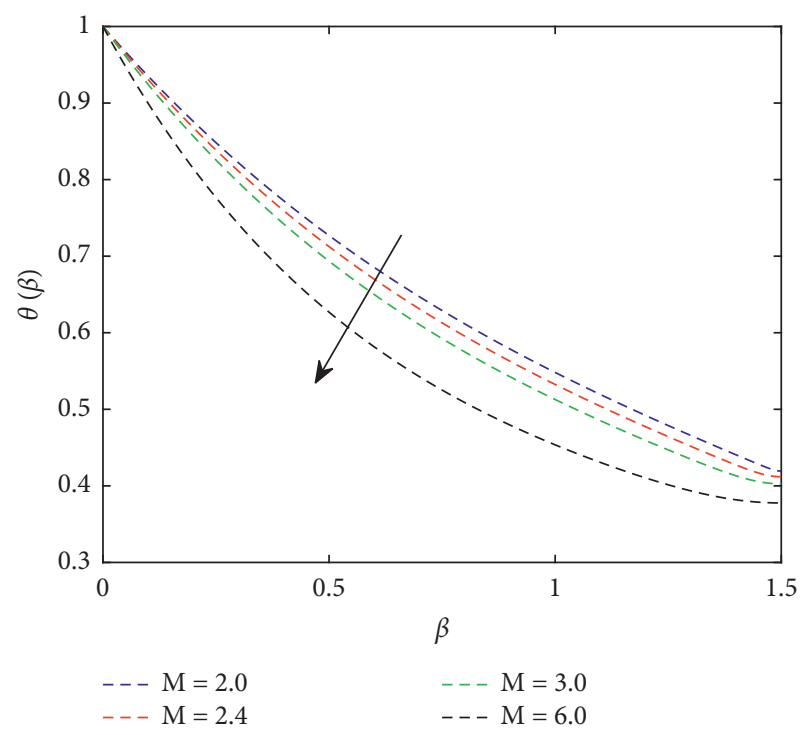

FiguRE 7: Characteristics of $M$ on temperature profile.

$k^{\prime}=f_{5}, k^{\prime \prime}=f_{6}, \theta=f_{7}, \theta^{\prime}=f_{8}, \phi=f_{9}$, and $\phi^{\prime}=f_{10}$. The given matrix form is

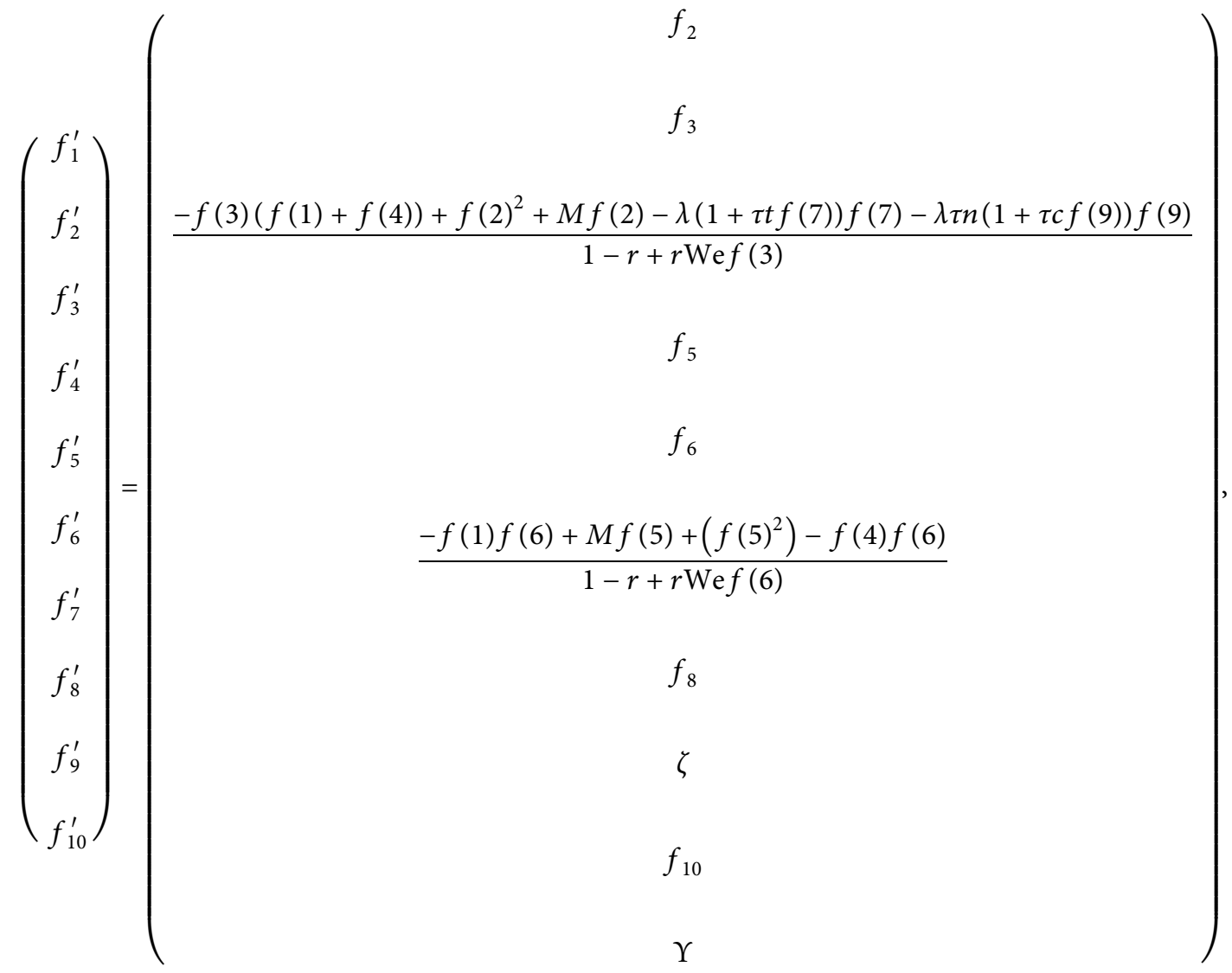


for

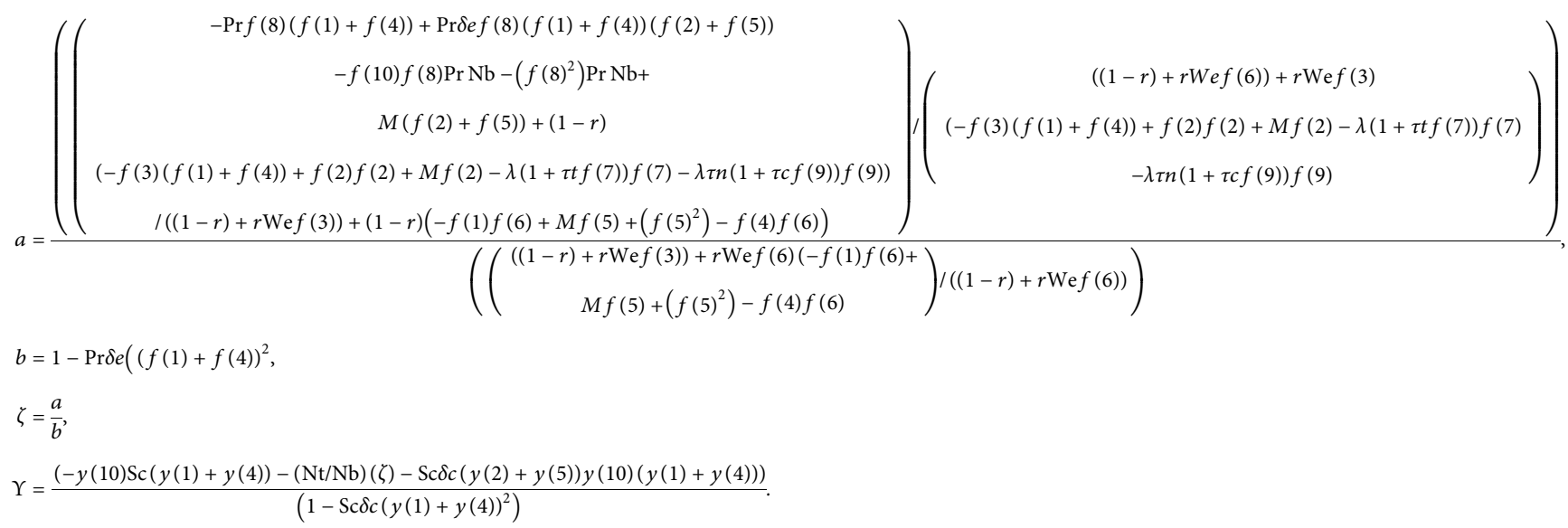

The vector form of boundary conditions is given as follows:

$$
\left(\begin{array}{l}
f_{0}(1) \\
f_{0}(2) \\
f_{0}(4) \\
f_{0}(5) \\
f_{0}(7) \\
f_{0}(9) \\
f_{b}(3) \\
f_{b}(6) \\
f_{b}(8) \\
f_{b}(10)
\end{array}\right)=\left(\begin{array}{l}
0 \\
1 \\
0 \\
1 \\
1 \\
1 \\
0 \\
0 \\
0 \\
0
\end{array}\right) .
$$

The vector form of boundary conditions is given as follows:

$$
\left(\begin{array}{l}
f_{0}(1) \\
f_{0}(2) \\
f_{0}(4) \\
f_{0}(5) \\
f_{0}(7) \\
f_{0}(9) \\
f_{b}(3) \\
f_{b}(6) \\
f_{b}(8) \\
f_{b}(10)
\end{array}\right)=\left(\begin{array}{l}
0 \\
1 \\
0 \\
1 \\
1 \\
1 \\
0 \\
0 \\
0 \\
0
\end{array}\right) .
$$

Numerical integration of the bvp4c Matlab solver is used to solve (22).

\section{Results and Discussion}

The characteristics of velocity against $r$ are illustrated by the graph in Figure 2. Physically, an enlargement in the values of $r$ reduces the resistance to flow for the case of small viscosity shear-thinning fluid by enhancing the fluid velocity. By this fact and as can be seen from Figure 2, the values of $r$ extremely enlarge as the velocity of nanofluid is deceased. Figure 3 is plotted to demonstrate the behaviors of $\tau c$ on the velocity of the fluid. As the value of $\tau c$ is upgraded from 0.2 to 0.4 , the nanofluid velocity is enhanced. Figures 4 and 5 are plotted to investigate the characteristic of mixed convection (or thermal buoyancy) parameter $\lambda$ and nonlinear mixed convection due to temperature $\tau t$ on velocity profile along $x$-axis, respectively. As we seen from the graphs, the influences of these parameters are similar.

The behavior of $\mathrm{Nb}$ (Brownian motion parameter) is illustrated on temperature by Figure 6 . Physically, $D_{B}$ (Brownian diffusion coefficients) and $\mathrm{Nb}$ (Brownian motion parameter) are directly proportional to each other. For this case, nanofluid temperature increases as both Brownian diffusion coefficients $\left(D_{B}\right)$ and Brownian motion parameters $(\mathrm{Nb})$ were enhanced. Moreover, the graph of Figure 6 is uphill due to Brownian motion parameter resulting in an increment in temperature nanofluid.

The impact of magnetic parameter $M$ is examined on the temperature graph as shown in Figure 7. Physically, viscous force and electromagnetic force are inversely and directly proportional to magnetic parameter, respectively. For both 


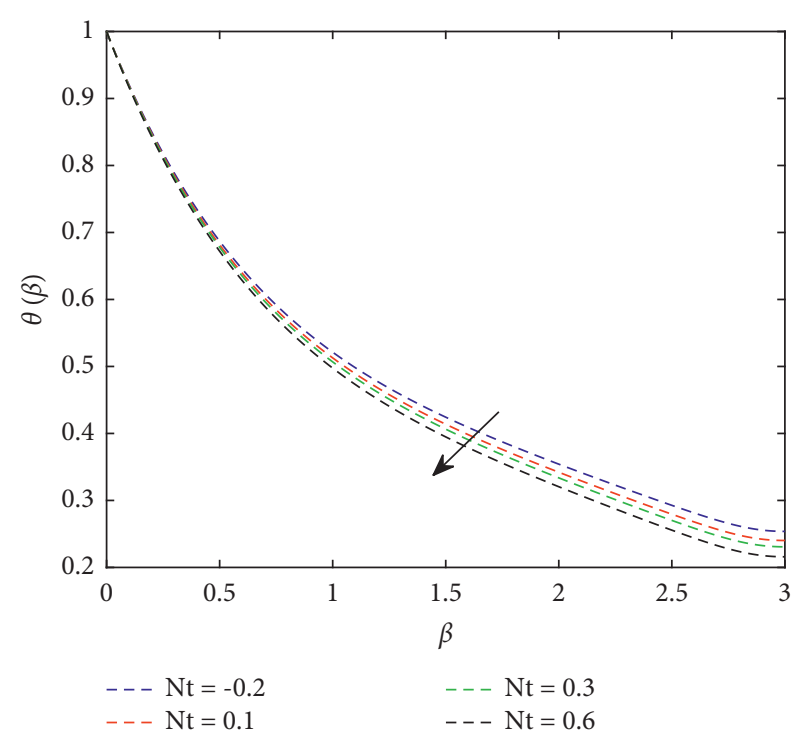

Figure 8: Characteristics of $\mathrm{Nt}$ on temperature profile.

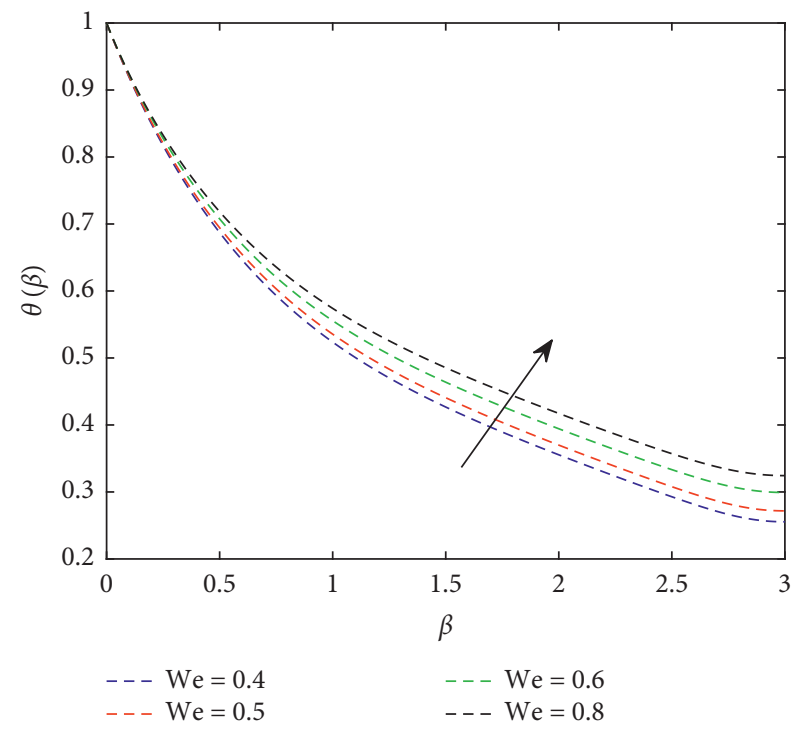

Figure 9: Characteristics of We on temperature profile.

physical and graphical descriptions, Figure 7 confirms that as the values of magnetic parameter $M$ increase, the temperature graph decreases.

The influence of the Weissenberg number We on temperature of nanofluid is depicted in Figure 8. The ratio of a specific process time to the relaxation time of the fluid is the physical determination of the Weissenberg number. Therefore, an increment in the Weissenberg number We resulted in an enlargement of temperature of nanofluid. The effect of thermophoretic force $(\mathrm{Nt})$ is developed in temperature of nanofluid as sketched in Figure 9. Physically, an elevation of the temperature of the fluids and more thickness of thermal boundary layers are the result of pushing away nanoparticle from hot boundary toward fluid. Therefore, enlargement in the values of $\mathrm{Nt}$ resulted in downward graph of temperature of nanofluid. Figure 10 reports the impact of Prandtl number (Pr) on the temperature profile. Physically, the fluid with high

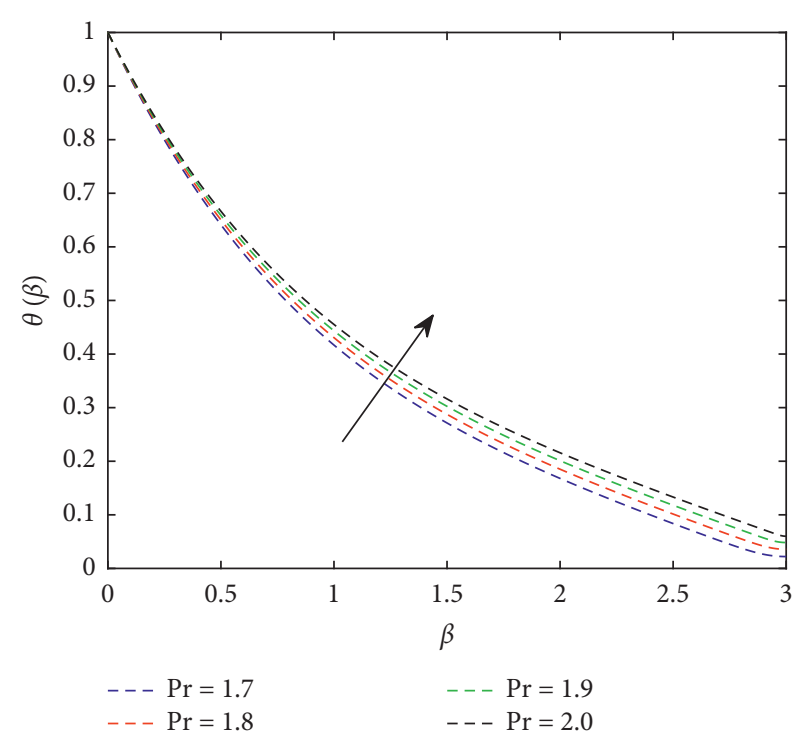

FIgURE 10: Characteristics of Pr on temperature profile.

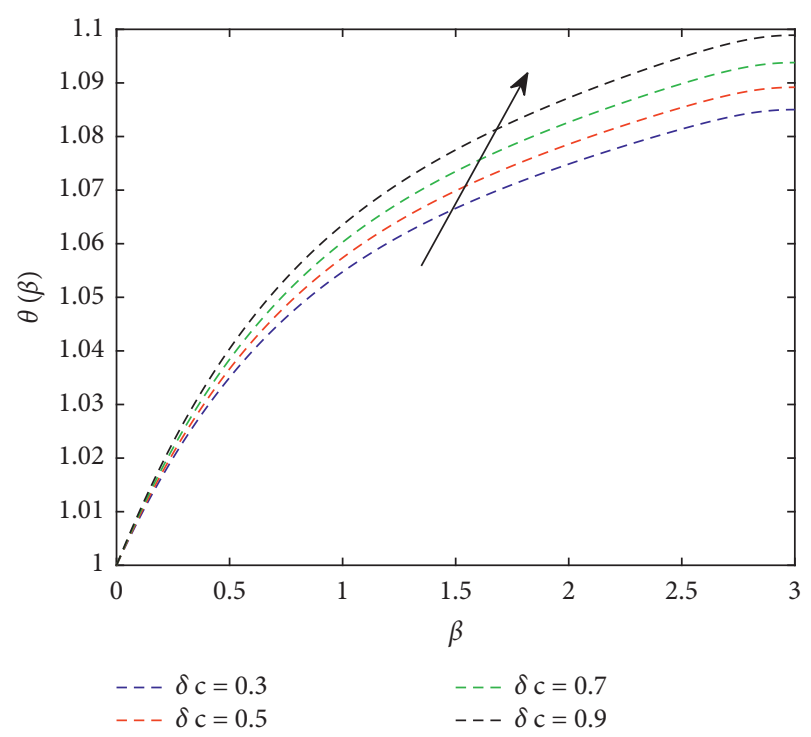

Figure 11: Characteristics of $\delta_{c}$ on concentration profile.

Prandtl number has low thermal diffusion when compared with viscous diffusion. As a result, when the values of Prandtl number are enlarged, temperature graph is increased.

Figure 11 reports the characteristics of $\delta_{c}$ on the concentration of nanofluid particles. An increment of the modulus of $\delta_{c}$ corresponds to an enlargement in the concentration of nanofluid particles.

The importance of the relaxation time parameter (Cattaneo-Christov heat flux model), $\delta_{e}$, is explained in concentration of nanofluid as plotted in Figure 12. The time needed by the fluid particle to transfer the heat energy to the neighboring particles is physical description of thermal relaxation time (Cattaneo-Christov heat flux model). This shows that thermal relaxation time is the time needed for material particles to transfer heat to adjacent particles. Therefore, thermal relaxation parameter increased for the 


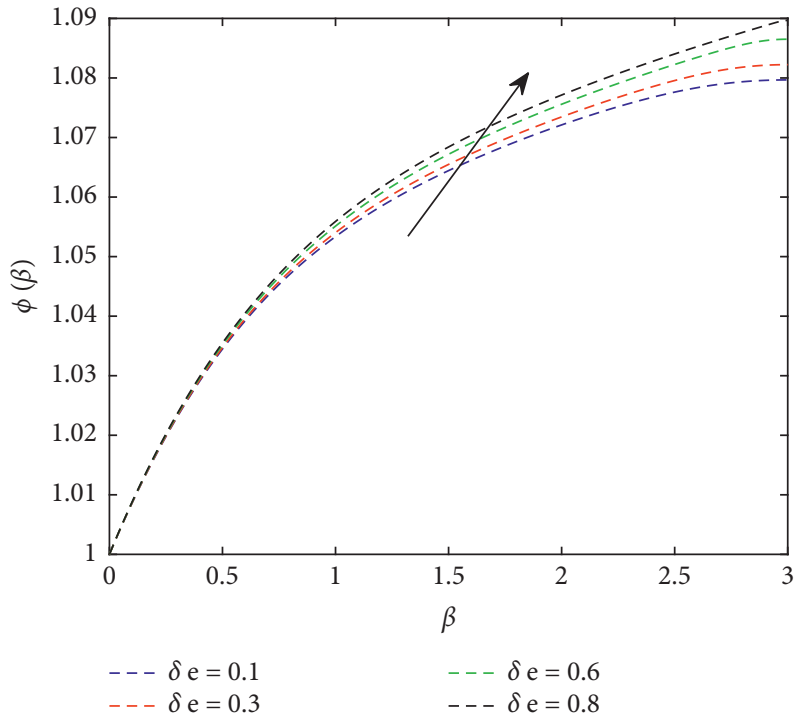

FIgURE 12: Characteristics of $\delta_{e}$ on concentration profile.

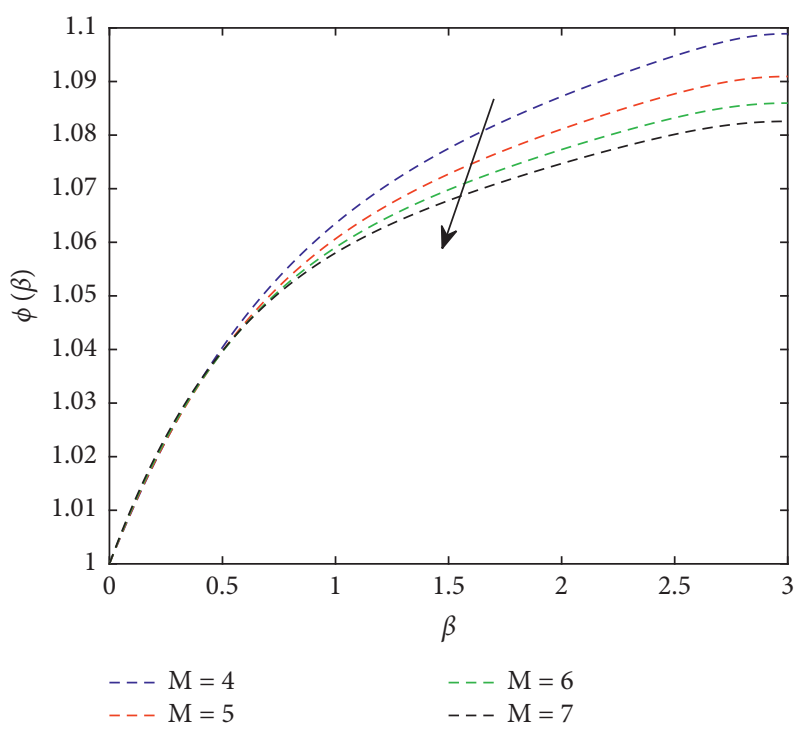

FIgURE 13: Characteristics of $M$ on concentration profile.

case of small heat transfer to the fluid from the surfaces of the sheets. Moreover, the absolute value of relaxation time parameter is enlarged as concentration nanofluid is developed. The influence of magnetic parameter $(M)$ is discussed on the concentration graph as plotted in Figure 13. As we can see from the graph, an enlargement of the values of magnetic parameter $M$ causes a decrease in the concentration graph. Figure 14 depicts the behavior of Schmidt number (Sc) on concentration profile. Physically, the ratio of momentum to mass diffusivity is said to be Schmidt number (Sc). Thus, as the values of Sc increase, the graph of concentration profile increases.

Figures 15-17 give an analysis of the skin friction coefficient, local Nusselt number, and Sherwood number for different values of nonlinear mixed convection due to temperature $\tau t$, thermophoresis parameter $\mathrm{Nt}$, and

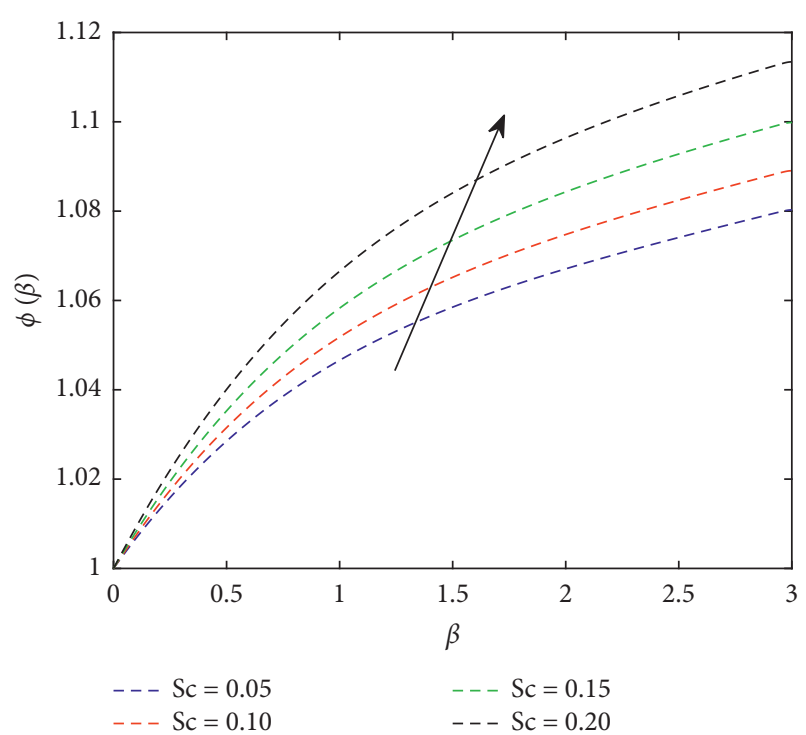

Figure 14: Characteristics of Sc on concentration profile.

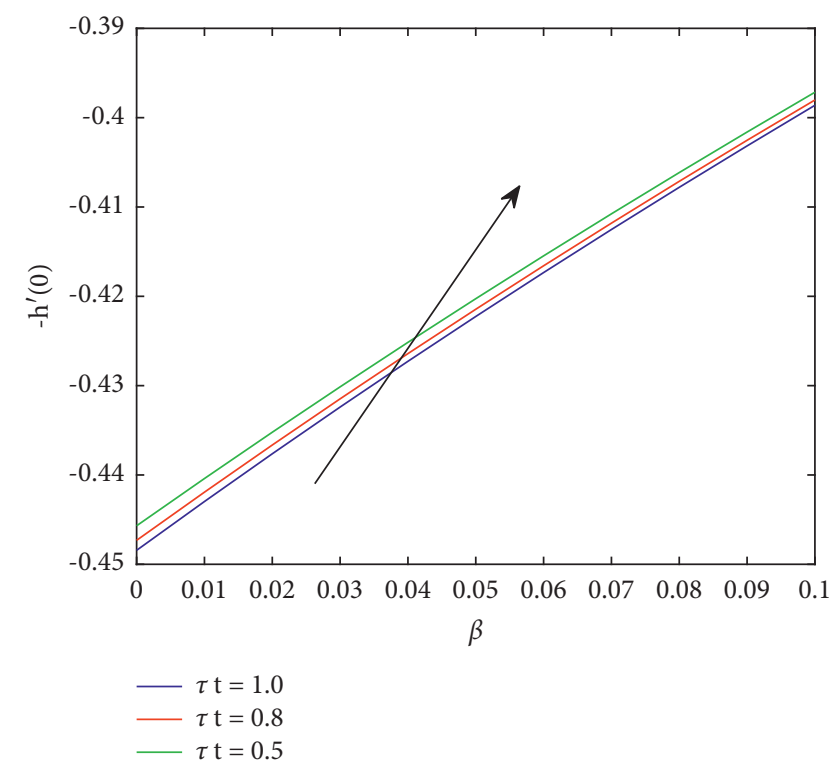

FIGURE 15: Characteristics of $\tau t$ on skin friction coefficient number.

concentration relaxation parameter $\delta_{c}$. An increment in the values of all the mentioned parameters resulted in a decrement in Figures 15-17.

The influence of various governing parameters on the rate of entropy generation and Bejan number will be described below. Figures 18 and 19 report the characteristics of $\mathrm{Br}$ on entropy generation number and Bejan number, respectively. As the values of $\mathrm{Br}$ increase, the entropy generation rate increases, but a decreasing trend of Bejan number is observed as the values of $\mathrm{Br}$ grow. It is interesting to note that zero entropy generation is observed far away from the surface of the stretching sheet. Dominance of viscous effects over mass and heat transfer by entropy generation is enhanced and Bejan number is decreased due to enlargement of $\mathrm{Br}$. 

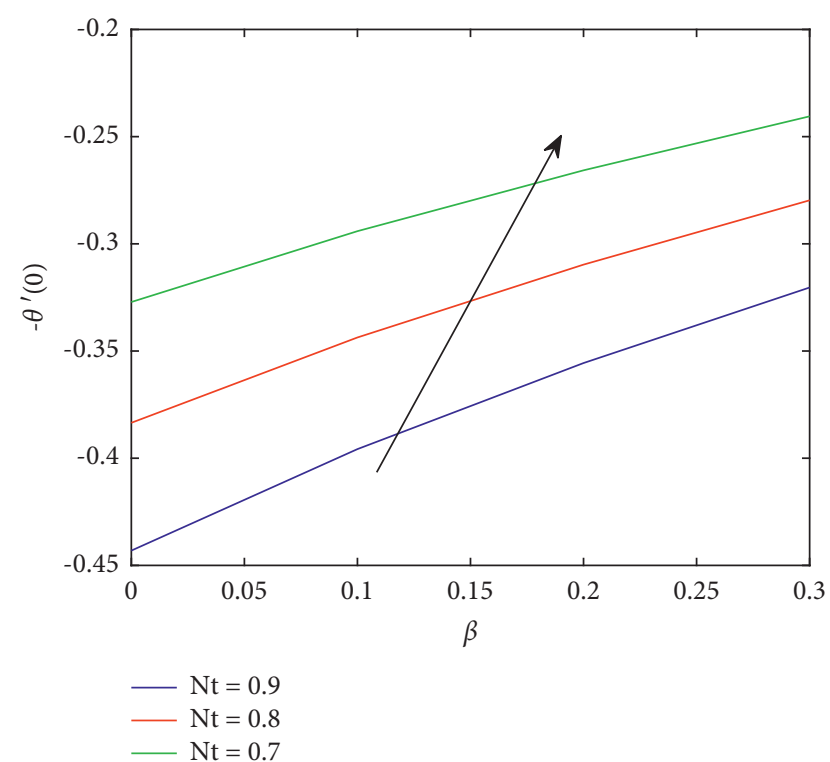

FIgURE 16: Characteristics of Nt on local Nusselt number.

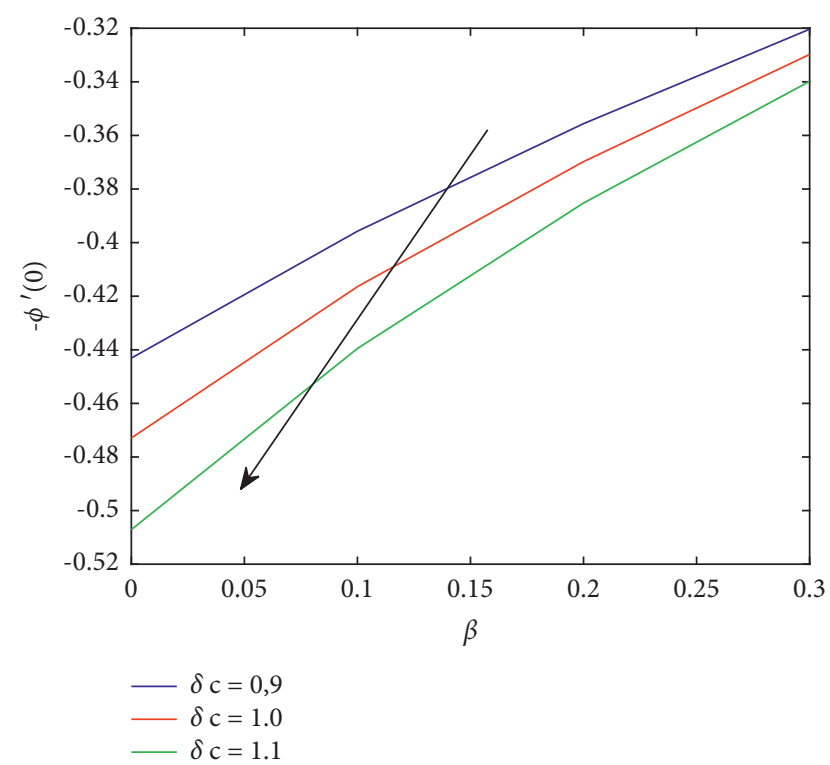

FIgURE 17: Characteristics of $\delta_{c}$ on Sherwood number.

The characteristics of $B$ on entropy generation number and Bejan number are reported by Figures 20 and 21, respectively. Similar impacts have been presented by increasing both entropy generation number and Bejan number. That means, as we see from the figures, increasing the values of $B$ resulted in

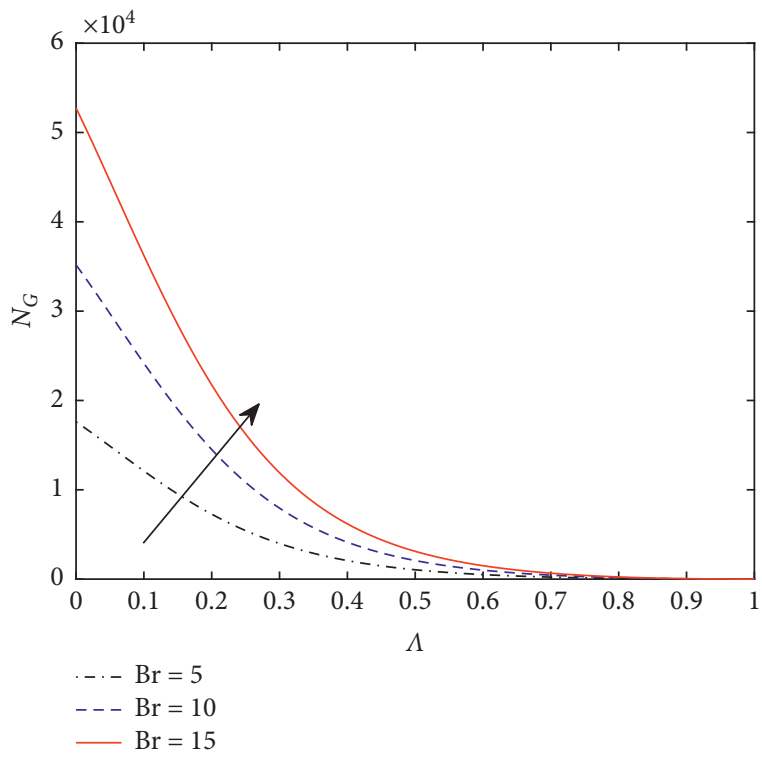

Figure 18: Characteristics of $\mathrm{Br}$ on entropy generation number (NG).

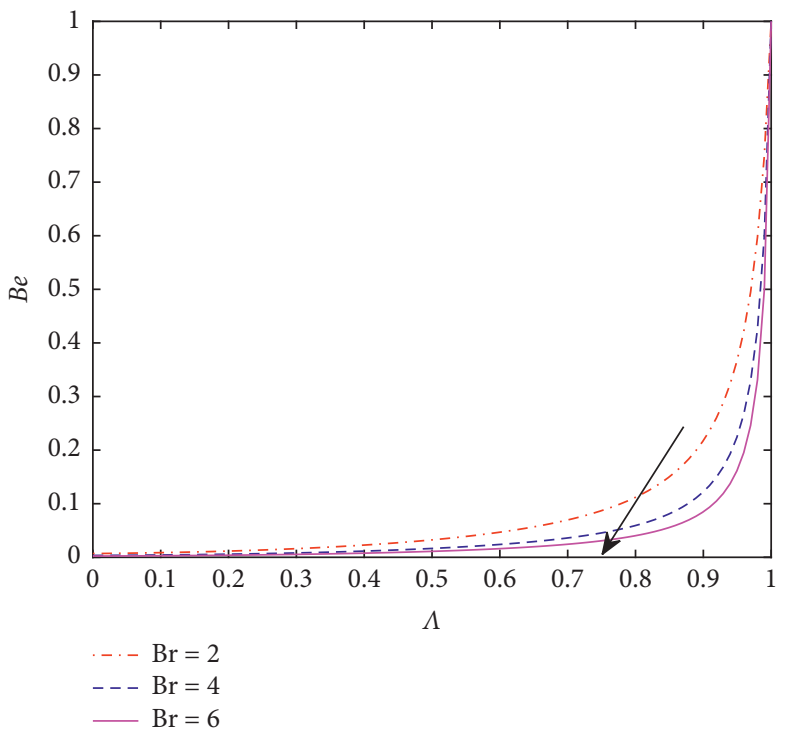

Figure 19: Characteristics of $\mathrm{Br}$ on Bejan number (Be).

enhancement of both entropy generation number and Bejan number of the problem under consideration. Figure 22 reports the influence of concentration profile $\beta 2$ on Bejan number. As we understand from Figure 22, the graph of Bejan number (Be) increases when the values of $\beta 2$ enlarge. 


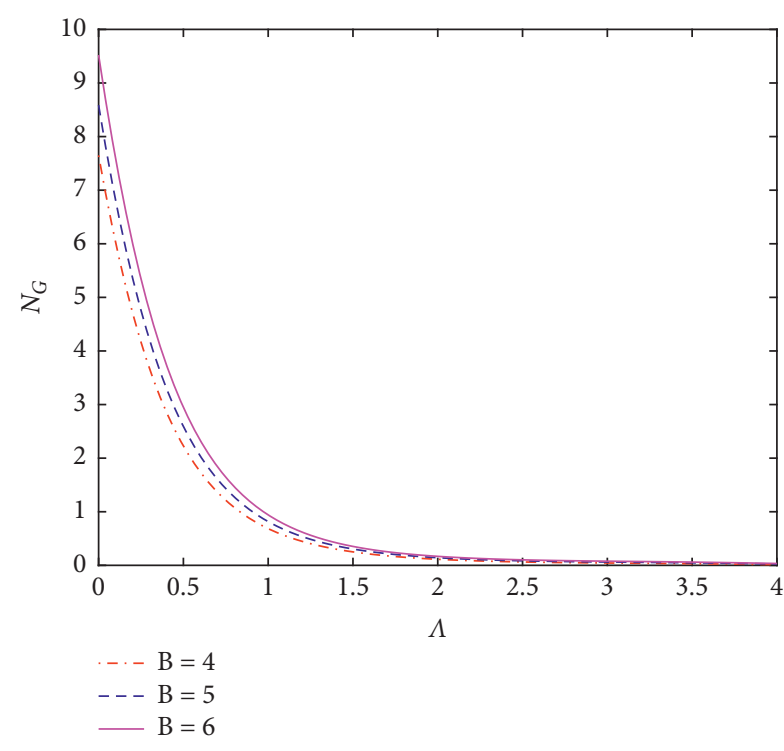

Figure 20: Characteristics of $B$ on entropy generation number (NG).

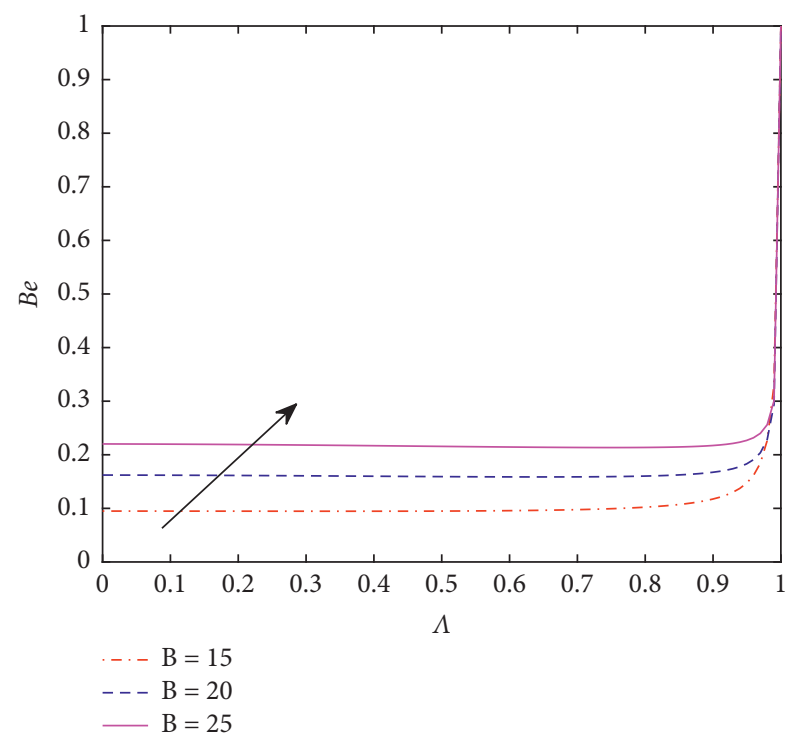

Figure 21: Characteristics of $B$ on Bejan number (Be).

In Table 1, comparison of this paper with the open literature of the previous work is reported. More agreement is recorded when we compare the result of this paper with the previous literature on the various values of $M$ according to the presentation in this table. Moreover, Table 2 discusses the characteristics of $r, \tau c, \mathrm{Pr}$, and $\mathrm{Sc}$ on $-h^{\prime \prime}(\eta),-k^{\prime \prime}(\eta),-\theta^{\prime}(\eta)$, and $-\phi^{\prime}(\eta)$. A thorough discussion on the behavior of those parameters is reported in this table.

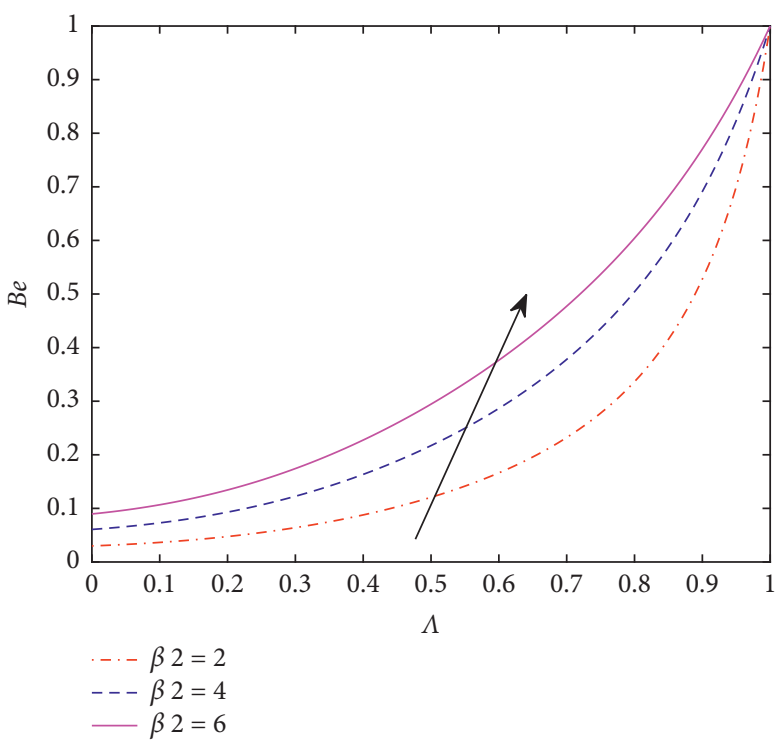

Figure 22: Characteristics of Br on Bejan number (Be).

TABle 1: Comparison showing that this article agrees with the literature of $f^{\prime \prime}(0)$.

\begin{tabular}{lcc}
\hline$M$ & Ref [50] & This paper \\
\hline 0.0 & -1.0000 & -1.000046 \\
0.5 & -1.18034 & -1.180340 \\
1.0 & -1.414214 & -1.414214 \\
2.0 & - & -1.764738 \\
3.0 & - & -2.048698 \\
4.0 & - & -2.290626 \\
\hline
\end{tabular}

The authors assumed the parameter $B=\beta 1$.

TABLE 2: Computed values for skin friction coefficient, local Nusselt number, and Sherwood number for this manuscript.

\begin{tabular}{lccccccc}
\hline$r$ & $\tau c$ & $\operatorname{Pr}$ & $\mathrm{Sc}$ & $-h^{\prime \prime}(\eta)$ & $-k^{\prime \prime}(\eta)$ & $-\theta^{\prime}(\eta)$ & $-\phi^{\prime}(\eta)$ \\
\hline 0.2 & 0.2 & 2.0 & 0.3 & 3.312768 & 3.429777 & 1.185088 & 0.119707 \\
0.3 & & & & 3.764443 & 3.913524 & 1.177402 & 0.114871 \\
0.4 & & & & 4.713001 & 4.981438 & 1.164543 & 0.109524 \\
0.5 & & & & 12.125562 & 7.155310 & 1.110244 & 0.099446 \\
& 0.3 & & & 3.309783 & 3.429812 & 1.185089 & 0.119914 \\
& 0.4 & & & 3.306798 & 3.429842 & 1.185090 & 0.120121 \\
& 0.5 & & & 3.303812 & 3.429883 & 1.185091 & 0.120329 \\
& 2.1 & & 3.312107 & 3.429788 & 1.157631 & 0.117182 \\
& 2.2 & & 3.311488 & 3.429797 & 1.132022 & 0.114823 \\
& 2.3 & & 3.310907 & 3.429806 & 1.108063 & 0.112614 \\
& 2.4 & & 3.310360 & 3.429815 & 1.085583 & 0.110539 \\
& & & 0.4 & 3.312837 & 3.429776 & 1.191370 & 0.131638 \\
& & & 0.5 & 3.312927 & 3.429775 & 1.199489 & 0.146965 \\
& & & 0.6 & 3.313048 & 3.429773 & 1.210305 & 0.167227 \\
& & & 0.7 & 3.313218 & 3.429770 & 1.225225 & 0.194895 \\
\hline
\end{tabular}




\section{Conclusions}

In this article, we investigate the influence of entropy generation and magnetic field on a thin film flow of tangent hyperbolic fluid flow which is an incompressible, laminar, viscous, and steady flow past a three-dimensional stretching surface under forced and natural convection flow condition. Cattaneo-Christov heat and mass flux model is employed in the governing problem of this study. This article outputs are given as follows:

(1) Velocity along $x$-axis decreases as both the values of power-law index parameter $r$ and Schmidt number Sc increase.

(2) Mixed convection (or thermal buoyancy) parameter $\lambda$ and nonlinear mixed convection due to temperature $\tau t$ show similar agreement on velocity profile along the $x$-axis.

(3) As the values of thermophoresis parameter $\mathrm{Nt}$ and magnetic field parameter $M$ increase, the temperature profile decreases.

(4) As the value of concentration relaxation parameter $\delta_{c}$ decreases, the concentration profile increases.

(5) Impact of nonlinear mixed convection due to concentration $\tau c$ and Schmidt number Sc on concentration profile is similar when their values are uphill in Table 2.

(6) Nonlinear mixed convection due to temperature $\tau t$, thermophoresis parameter $\mathrm{Nt}$, and concentration relaxation parameter $\delta_{c}$ have similar impact on the skin friction coefficient number, local Nusselt number, and Sherwood number.

(7) Brinkman number $\mathrm{Br}$ and parameter $B$ have opposite impact on entropy generation number NG and Bejan number Be.

Investigation of the application of unsteady Dufour and Soret effect with cylindrical form of tangent hyperbolic fluid at thin film flow is the future work of the authors.

\section{Nomenclature}

$\tau t$ : Nonlinear mixed convection due to temperature

$\tau c$ : Nonlinear mixed convection due to concentration

$\tau n$ : $\quad$ Ratio of concentration to thermal buoyancy forces

$\lambda$ : $\quad$ Mixed convection (or thermal buoyancy) parameter

$\beta 1$ : $\quad$ Temperature difference parameter for entropy

$\beta 2$ : $\quad$ Concentration difference variable

$w, v, u$ : Velocity components in directions

$y$ : $\quad$ Direction normal to the surfaces

$x$ : Direction along the surfaces

$h, k: \quad$ Dimensionless velocities

$T: \quad$ Temperature of the fluids

C: $\quad$ Concentration of the fluids

$\mathrm{Nb}$ : Motion of Brownian parameter

$r$ : $\quad$ Power-law index parameter

Sc: $\quad$ Schmidt number

M: $\quad$ Magnetic field parameter

Nt: Parameter of thermophoresis

NG: Entropy generation number
We: Weissenberg number

Br: Brinkman number

l1: Diffusion variable

Be: Bejan number

$\mathrm{Sh}_{x}$ : Local Sherwood number

$\mathrm{Nu}_{x}$ : Local Nusselt number

$\operatorname{Re}_{x}$ : Local Reynolds number

Gr: Grashof number

Pr: $\quad$ Prandtl number.

\section{Greek letters}

$\rho$ : Density of the fluid

$v$ : Kinematic viscosity

$\mu$ : Dynamic viscosity

$\theta$ : Dimensionless temperature

$\phi:$ Dimensionless concentration

$\delta_{e}$ : Temperature relaxation parameter

$\delta_{c}$ : Concentration relaxation parameter

$\eta$ : Similarity variable.

Subscripts

$w$ : Surface condition

$\infty$ : Free stream condition.

\section{Data Availability}

The data that support the findings of this study are available from the corresponding author upon reasonable request.

\section{Conflicts of Interest}

The authors declare that they have no conflicts of interest.

\section{Authors' Contributions}

Both authors have made substantive contributions to the article and assume full responsibility for its content. The authors read and approved the final manuscript.

\section{References}

[1] A. Bejan, "A study of entropy generation in fundamental convective heat transfer," Journal of Heat Transfer, vol. 101, no. 4, pp. 718-725, 1979.

[2] A. Bejan, Entropy Generation Minimization: The Method of Thermodynamic Optimization of Finite-Size Systems and Finite-Time Processes, CRC Press, Boca Raton, FL, USA, 1995.

[3] D. Lin, X. Yuan, and X. Su, "Local entropy generation in compressible flow through a high pressure turbine with delayed detached eddy simulation," Entropy, vol. 19, no. 29, 2017.

[4] N. S. Khan, Q. Shah, A. Bhaumik, P. Kumam, P. Thounthong, and I. Amiri, "Entropy generation in bioconvection nanofluid flow between two stretchable rotating disks," Scientific Reports, vol. 10, no. 1, p. 4448, 2020.

[5] A. A. Opanuga, O. O. Agboola, H. I. Okagbue, and A. M. Olanrewaju, "Hall current and ion-slip effects on the entropy generation of couple stress fluid with velocity slip and temperature jump," International Journal of Mechanical Sciences, vol. 12, pp. 1998-4448, 2018.

[6] A. Bibi and H. Xu, "Entropy generation analysis of peristaltic flow and heat transfer of a jeffery nanofluid in a horizontal channel under magnetic environment," Mathematical 
Problems in Engineering, vol. 2019, Article ID 2405986, 13 pages, 2019.

[7] Y. Ji, H.-C. Zhang, X. Yang, and L. Shi, "Entropy generation analysis and performance evaluation of turbulent forced convective heat transfer to nanofluids," Entropy, vol. 19, no. 3, p. 108, 2017.

[8] G. C. Shit and S. Mandal, "Entropy analysis on unsteady MHD flow of casson nanofluid over a stretching vertical plate with thermal radiation effect," International Journal of Computational and Applied Mathematics, vol. 6, no. 2, 2020.

[9] B. J. Gireesha, C. T. Srinivasa, N. S. S. kumar, M. Macha, J. K. Singh, and B. Mahanthesh, "Entropy generation and heat transport analysis of casson fluid flow with viscous and joule heating in an inclined porous microchannel," Journal of Process Mechanical Engineering, vol. 233, pp. 1-12, 2019.

[10] M. I. Khan and S. A. Khan, "Entropy generation in radiative flow of Ree-Eyring fluid due to due rotating disks," International Journal of Numerical Methods HFF, vol. 29, 2019.

[11] M. Leonid, "Entropy and entropy production: old misconceptions and new breakthroughs," Entropy, vol. 15, pp. 1152-1170, 2013.

[12] R. M. Velasco, L. Scherer García-Colín, and F. J. Uribe, "Entropy Production: its role in non-equilibrium thermodynamics," Entropy, vol. 13, no. 1, pp. 82-116, 2011.

[13] G. Gallavotti, "Entropy production and thermodynamics of nonequilibrium stationary states: a point of view," Chaos, vol. 14, no. 3, pp. 680-690, 2004.

[14] C. Jundika, Kurnia, C. Desmond, L. C. Lim, L. Jiang, and P. A. Sasmito, "Entropy generation and heat transfer performance in microchannel cooling," Entropy, vol. 21, p. 191, 2019.

[15] B. Sahin, "Numerical analysis of entropy generation in a square cavity flled with boron water nanofuid," Journal of the Brazilian Society of Mechanical Sciences and Engineering, vol. 42, p. 146, 2020.

[16] H. Soltanipour, A. Gharegoz, and M. B. Oskooee, "Numerical study of magnetic field effect on the ferro-fluid forced convection and entropy generation in a curved pipe," Journal of the Brazilian Society of Mechanical Sciences and Engineering, vol. 42, no. 135, 2020.

[17] A. Riaz, R. Ellahi, S. M Sait, and T. Muhammad, "Magnetized Jerey nanouid with energy loss in between an annular part of two micro non-concentric pipes," Energy Sources, Part a: Recovery, Utilization, and Environmental Effects, vol. 74, 2020.

[18] A. Riaz, M. M. Bhatti, R. Ellahi, Z. Ahmed, and S. M. Sait, "Mathematical analysis on an asymmetrical wavy motion of blood under the influence entropy generation with convective boundary conditions," Symmetry, vol. 12, no. 102, 2020.

[19] T. Gul, I. Haleem, I. Ullah et al., "The study of the entropy generation in a thin film flow with variable fluid properties past over a stretching sheet," Advances in Mechanical Engineering, vol. 10, no. 11, pp. 1-15, 2018.

[20] G. Sarojamma, K. Vajravelu, and K. Sreelakshmi, "A study on entropy generation on thin film flow over an unsteady stretching sheet under the influence of magnetic field, thermocapillarity, thermal radiation and internal heat generation/ absorption," Communications in Numerical Analysis, vol. 2017, pp. 141-156, 2017.

[21] Z. Shah, E. O. Alzahrani, A. Dawar, W. Alghamdi, and M. Z. Ullah, "Entropy generation in MHD second-grade nanofluid thin film flow containing CNTs with CattaneoChristov heat flux model past an unsteady stretching sheet," Applied Sciences, vol. 10, Article ID 2720, 2020.
[22] M. A. Siddiqui, A. Riaz, I. Khanc, and K. S. Nisar, "Augmentation of mixed convection heat transfer in a lid-assisted square enclosure utilizing micropolar fluid under magnetic environment: a numerical approach," Respiration Physiology, vol. 18, Article ID 103245, 2020.

[23] B. K. Jha, P. B. Malgwi, and B. Aina, "Hall effects on MHD natural convection flow in a vertical microchannel," Alexandria Engineering Journal, vol. 57, no. 2, pp. 983-993, 2018.

[24] A. H. Khatera, D. K. Callebautb, S. F. Abdul-Aziza, and T. N. Abdelhamee, "Potential symmetry and invariant solutions of fokker-planck equation in cylindrical coordinates related to magnetic field diffusion in magnetohydrodynamics including the hall current," Phys Condensed Matter, vol. 50, 2006.

[25] D. Pal and B. Talukdar, "Influence of hall current and thermal radiation on MHD convective heat and mass transfer in a rotating porous channel with chemical reaction," International Journal of Engineering Mathematics, vol. 2013, Article ID 367064, 11 pages, 2013.

[26] A. Abiodun, Opanuga, O. Olasunmbo, A. Agboola, G. Jacob, and I. Hilary, "Okagbue, "Entropy generation analysis of Hall current efect on MHD micropolar fuid fow with rotation efect," SN Applied Sciences, vol. 2, no. 18, 2020.

[27] A. S. Liao, S. Li, P. Hartigan et al., "Numerical simulation of an experimental analogue of a planetary magnetosphere," High Energy Density Physics, vol. 17, 2015.

[28] K. J. Basant and B. Peter, "Malgwi, "Combined efects of hall and ion-slip current on MHD free convection flow in a vertical micro channel," SN Applied Sciences, vol. 1, p. 1163, 2019.

[29] R. N. Barik, G. C. Dash, and M. Kar, "Free convection heat and mass transfer MHD flow in a vertical porous channel in the presence of chemical reaction," Journal of Fluids, vol. 2013, Article ID 297493, 12 pages, 2013.

[30] S. Yeh, T. J. Chen, and J. C. Leong, "Analytical solution for MHD flow of a magnetic fluid within a thick porous annulus," Journal of Applied Mathematics, vol. 2014, Article ID 931732, 10 pages, 2014.

[31] M. Usman, Z. Naheed, A. Nazir, and S. T. Mohyud-Din, "On MHD flow of an incompressible viscous fluid," Journal of the Egyptian Mathematical Society, vol. 22, no. 2, pp. 214-219, 2014.

[32] B. Singh and A. Bhardwaj, "Wavelet optimized finite difference mesh for MHD flow in a circular duct," Computers \& Mathematics with Applications, vol. 67, no. 8, pp. 1582-1594, 2014.

[33] K. Ganesh Kumar, Rizwan-ul-Haq, N. G. Rudraswamy, and B. J. Gireesha, "Effects of mass transfer on MHD three dimensional flow of a Prandtl liquid over a flat plate in the presence of chemical reaction," Results in Physics, vol. 7, pp. 3465-3471, 2017.

[34] S. Joya Saha and L. K. Saha, "Transient mixed convection boundary layer flow of an incompressible fluid Past a Wedge in presence of magnetic field," Applied and Computational Mathematics, vol. 8, no. 1, pp. 9-20, 2019.

[35] A. Abdullah, A. A. Al-Rashed, J. N. S. Ahmed, H. M. T. Khaleed, T. M. Yunus, and K. S. N.A. Khan, "Mixed Convection Opposing flow in a vertical porous annulus-two temperature model," IOP Conference Series: Materials Science and Engineering, vol. 149, Article ID 012214, 2016.

[36] A. A. A. Arani, M. Abbaszadeh, and A. Ardeshiri, "Mixed convection fluid flow and heat transfer and optimal distribution of discrete heat sources location in a cavity filled with nanofluid," Transport Phenomena in Nano and Micro Scales, vol. 5, no. 1, pp. 30-43, 2017. 
[37] M. K. A. Mohamed, M. Z. Salleh, and A. Ishak, "Effects of viscous dissipation on mixed convection boundary layer flow past a vertical moving plate in a nanofluid," Journal of Advanced Research in Fluid Mechanics and Thermal Sciences, vol. 69, no. 2, pp. 1-18, 2020.

[38] I. Ammar, Alsabery, T. Tayebi et al., "Entropy generation and mixed convection flow inside a wavy-walled enclosure containing a rotating solid cylinder and a heat source," Entropy, vol. 22, p. 606, 2020.

[39] W. Ibrahim and T. Anbessa, "Hall and Ion slip effects on mixed convection flow of eyring-powell nanofluid over a stretching surface," vol. 2020, Article ID 4354860, 16 pages, 2020, https://www.researchgate.net/journal/ Advances-in-Mathematical-Physics-1687-9139.

[40] M. S. Hashmi, K. Al-Khaled, N. Khan, S. U. Khan, and I. Tlili, "Buoyancy driven mixed convection flow of magnetized Maxell fluid with homogeneous-heterogeneous reactions with convective boundary conditions," Results in Physics, vol. 19, Article ID 103379, 2020.

[41] M. Sajid, I. Pop, and T. Hayat, "Fully developed mixed convection flow of a viscoelastic fluid between permeable parallel vertical plates," Computers \& Mathematics with Applications, vol. 59, no. 1, pp. 493-498, 2010.

[42] K. Basant and O. Oni, "Mixed convection flow in a vertical channel with temperature dependent viscosity and flow reversal: an exact solution," International Journal of Heat and Technology, vol. 36, no. 2, pp. 607-613, 2018.

[43] K. Ahmad, Z. Hanouf, and A. Ishak, "Mixed convection Jeffrey fluid flow over an exponentially stretching sheet with magnetohydrodynamic effect," AIP Advances, vol. 6, Article ID 035024, 2016.

[44] N. Khan, Hossam, A. Nabwey, M. S. Hashmi, S. U. Khan, and I. Tlili, "A Theoretical Analysis for mixed convection flow of maxwell fluid between two infinite isothermal stretching disks with heat source/sink," Symmetry, vol. 12, no. 62, 2020.

[45] K. Basant, P. Jha, and B. Malgwi, "Hall and ion-slip effects on MHD mixed convection flow in a vertical microchannel with asymmetric wall heating," Engineering Reports, vol. 2, 2020.

[46] C. Jawali, M. Umavathi, A. Sheremet, and S. L. Patil, "Soret effects on the mixed convection flow using Robin boundary conditions," Heat Transfer-Asian Research, vol. 49, no. 154-179, 2020.

[47] W. Ibrahim and G. Gadisa, "Double stratified mixed convective flow of couple stress nanofluid past inclined stretching cylinder using Cattaneo-Christov heat and mass flux model," Advances in Theoretical and Mathematical Physics, vol. 2020, Article ID 4890152, 16 pages, 2020.

[48] M. B. Ashraf, T. Hayat, S. A. Shehzad, and A. Alsaedi, "Mixed convection radiative ow of three dimensional Maxwell uid over an inclined stretching sheet in presence of thermophoresis and convective condition," AIP Advances, vol. 5, Article ID 027134, 2015.

[49] I. Khan, N. A. Shah, and L. C. C. Dennis, "A scientifc report on heat transfer analysis in mixed convection ow of Maxwell uid over an oscillating vertical plate," Scientific Reports, vol. 8, Article ID 46975, 2020.

[50] M. I. Khan, T. A. Khan, S. Qayyum, T. Hayat, M. I. Khan, and A. Alsaedi, "Entropy generation optimization and activation energy in nonlinear mixed convection flow of a tangent hyperbolic nanofluid," The European Physical Journal Plus, vol. 133, no. 8, p. 329, 2018.

[51] K. G. Kumar, B. J. Gireesha, and R. S. R. Gorla, "Flow and heat transfer of dusty hyperbolic tangent fluid over a stretching sheet in the presence of thermal radiation and magnetic field,"
International Journal of Mechanical and Materials Engineering, vol. 13, no. 2, 2018.

[52] M. Naseer, M. Y. Malik, S. Nadeem, and A. Rehman, "The boundary layer flow of hyperbolic tangent fluid over a vertical exponentially stretching cylinder," Alexandria Engineering Journal, vol. 53, 2014.

[53] M. Khan, A. Rasheed, and T. Salahuddin, "Radiation and chemical reactive impact on tangent hyperbolic uid ow having double stratification," AIP Advances, vol. 10, Article ID 075211, 2020.

[54] F. Shahzad, M. Sagheer, and S. Hussain, "MHD tangent hyperbolic nanofluid with chemical reaction, viscous dissipation and Joule heating effects," AIP Advances, vol. 9, Article ID 025007, 2019.

[55] M. Naseer, M. Y. Malik, S. Nadeem, and A. Rehman, "The boundary layer flow of hyperbolic tangent fluid over a vertical exponentially stretching cylinder," Alexandria Engineering Journal, vol. 53, no. 3, pp. 747-750, 2014.

[56] T. Hayat, M. I. Khan, M. Waqas, and A. Alsaedi, "Stagnation point flow of hyperbolic tangent fluid with Soret-Dufour effects," Results in Physics, vol. 7, pp. 2711-2717, 2017.

[57] K. Ganesh Kumar, B. J. Gireesha, M. R. Krishanamurthy, and N. G. Rudraswamy, "An unsteady squeezed flow of a tangent hyperbolic fluid over a sensor surface in the presence of variable thermal conductivity," Results in Physics, vol. 7, pp. 3031-3036, 2017.

[58] K. U. Rehman, A. S. Alshomrani, M. Y. Malik, I. Zehra, and M. Naseer, "Thermo-physical aspects in tangent hyperbolic fluid flow regime: a short communication," Case Studies in Thermal Engineering, vol. 12, pp. 203-212, 2018.

[59] T. Hayat, M. I. Khan, M. Waqas, and A. Alsaedi, "Radiative flow of hyperbolic tangent liquid subject to Joule heating," Results in Physics, vol. 7, pp. 2197-2203, 2017.

[60] S. Nadeem and S. Akram, "Magnetohydrodynamic peristaltic flow of a hyperbolic tangent fluid in a vertical asymmetric channel with heat transfer," Acta Mechanica Sinica, vol. 27, no. 2, pp. 237-250, 2011.

[61] N. S. Akbar, S. Nadeem, R. U. Haq, and Z. H. Khan, "Numerical solutions of Magnetohydrodynamic boundary layer flow of tangent hyperbolic fluid towards a stretching sheet," Indian Journal of Physics, vol. 87, no. 11, pp. 1121-1124, 2013.

[62] A. Hussain, M. Y. Malik, T. Salahuddin, A. Rubab, and M. Khan, "Effects of viscous dissipation on MHD tangent hyperbolic fluid over a nonlinear stretching sheet with convective boundary conditions," Results in Physics, vol. 7, pp. 3502-3509, 2017.

[63] T. Hayat, A. Shafiq, and A. Alsaedi, "Characteristics of magnetic field and melting heat transfer in stagnation point flow of Tangent-hyperbolic liquid," Journal of Magnetism and Magnetic Materials, vol. 405, 2015.

[64] A. Shafiq, Z. Hammouch, and T. N. Sindhu, "Bioconvective MHD flow of Tangent hyperbolic nanofluid with Newtonian heating," International Journal of Mechanical Sciences, vol. 133, 2017.

[65] A. A. Alaidrous and M. R. Eid, "3-D electromagnetic radiative non-Newtonian nanofluid flow with Joule heating and higherorder reactions in porous materials," Scientific Reports, vol. 10, Article ID 14513, 2020.

[66] W. Ibrahim and T. Gizewu, "Tangent hyperbolic nanofluid with mixed convection flow: an application of improved Fourier and Fick's diffusion model," Heat Transfer-Asian Research, vol. 48, no. 8, pp. 4217-4239, 2019.

[67] W. Ibrahim and T. Gizewu, "Nonlinear mixed convection flow of a tangent hyperbolic fluid with activation energy," Heat Transfer, vol. 49, no. 5, pp. 2427-2448, 2020. 